\title{
El tiempo y la cultura constitucional ${ }^{1}$
}

Time and constitutional culture

o tempo e a cultura constitucional

Temps et culture constitutionnelle

时间与宪政文化

\section{Peter Häberle ${ }^{2}$ \\ Universidad de Friburgo - Alemania}

Revista Derechos en Acción ISSN 2525-1678/ e-ISSN 2525-1686

Año 5/Nํo 16 Invierno 2020 (21 junio a 20 septiembre), 59-125

DOl: https://doi.org/10.24215/25251678e416

Recibido: $01 / 07 / 2020$

Aprobado: 11/08/2020

1 La contribución original Zeit und Verfassungskultur forma parte de la obra colectiva Die Zeit, Escritos de la Fundación Carl Friedrich von Siemens, tomo 6, editado por A. Peisl y A. Mohler, 1983 e incluido en las páginas 289-343. (La pregunta por el tiempo - "tiempo" no como "nuestra época", sino como dimensión - nos descubre visiones sobre el ser del hombre y su posición en el mundo. Científicos naturalistas y humanistas tratan de responder en este libro a esta cuestión desde sus diferentes posiciones). La traducción fue realizada por Irene Weinmann de Knoop, Traductora Pública de Alemán (UBA) y la Lic. Sylvia Lenz, Docente de la Facultad de Ciencias Sociales (UBA), con conocimiento y autorización del autor. Peter Häberle autorizó a la Dirección y al Prof. Dr. Raúl Gustavo Ferreyra la publicación exclusiva en español en Revista Derechos en Acción.

2 Doctor en Derecho por la Universidad de Friburgo. Catedrático en las Universidades de Friburgo, Mannheim, Marburgo y Bochum. Catedrático de Derecho Público, Filosofía del Derecho y Derecho Eclesiástico en la Universidad de Bayreuth (Alemania), donde ejerce actualmente sus tareas docentes e investigadoras. Publicó más de 50 libros sobre Derecho Constitucional, Derechos Humanos, Filosofía del Derecho y temas afines y cerca de mil artículos, ensayos y notas en libros colectivos, revistas y periódicos de Alemania y del extranjero. Doctor honoris causa múltiple en Universidades europeas y latinoamericanas, entre ellos por la Universidad de Buenos Aires. 
Resumen: En el presente trabajo, el destacado jurista alemán, nos invita a reflexionar sobre el "tiempo" a la luz de la Constitución y la cultura constitucional. En el mismo, siguiendo su premisa general de que las constituciones son textos que poseen un significado jurídico y un significado cultural, nos recuerda que las mismas se nos presentan como garantes de la continuidad y el cambio. Así, el maestro Häberle nos enseña que la Constitución no es solamente un reglamento normativo, sino también la expresión de un estadio del desarrollo cultural, un medio para la auto-representación cultural de un pueblo, reflejo de su herencia cultural y fundamento de sus esperanzas. Nos apunta que el abordaje del problema del tiempo en el derecho constitucional se pone a prueba frente a la necesidad de la preservación de una específica herencia cultural en interés de las futuras generaciones. En ese sentido, sostiene que la Constitución debe pensarse desde un inicio teniendo en cuenta y asumiendo la responsabilidad por los que van a venir, "la Constitución de hoy lleva en si misma una parte de la Constitución del fututo", acota. En concreto, nos dejará dos interrogantes abiertos en ese sentido: el cuidado del medioambiente y los límites del endeudamiento del Estado.

Palabras clave: Constitución; Interpretación constitucional; cultura constitucional

Abstract: In this paper, the prominent German jurist Peter Häberle invites us to reflect on "time" based on the Constitution and constitutional culture. In it, following its general premise that constitutions are texts that have a legal and cultural meaning, it reminds us that they are presented to us as guarantors of change and continuity. Thus, Häberle teaches us that the Constitution is not only a normative regulation, but also the expression of a phase of cultural development; a implement for the cultural self-representation of a people, a reflection of their cultural heritage and the fundament of their hopes. He points out that the approach to the problem of time in constitutional law is tested against the need to preserve a specific cultural heritage in the interest of future generations. In this sense, he argues that the Constitution should be thought from the beginning taking into account and assuming responsibility for those who are to come, "the Constitution of today carries in itself a part of the Constitution of the future," he says. Specifically, it will leave us two open questions in this regard: caring for the environment and the limits of the State's indebtedness. 
Keywords: Constitution; Constitutional interpretation; constitutional culture

Resumo: No presente trabalho, o proeminente jurista alemão convidanos a reflectir sobre o "tempo" à luz da Constituição e da cultura constitucional. Nele, seguindo sua premissa geral de que as constituições são textos com significado jurídico e significado cultural, recorda-nos que as mesmas nos são apresentadas como garantes da continuidade e da mudança. Assim, o mestre Häberle ensina-nos que a Constituição não é apenas um regulamento normativo, mas também a expressão de uma etapa de desenvolvimento cultural, um meio para a auto-representação cultural de um povo, um reflexo de sua herança e fundamento de suas esperanças. Ele aponta-nos que a abordagem do problema do tempo no direito constitucional é posto à prova frente a necessidade da preservação de uma específica herança cultural específico, no interesse das gerações futuras. Neste sentido, defende que a Constituição deve ser pensada desde 0 início tendo em conta e assumindo a responsabilidade por aqueles que virão, "a Constituição de hoje traz dentro de si uma parte da Constituição do futuro", observa. Especificamente, vai nos deixar com duas perguntas nesse sentido: o cuidado do ambiente e os limites do endividamento do Estado.

Palavras-chave: Constituição; interpretação constitucional; cultura constitucional

Résumé: Dans cet article, l'éminent juriste allemand nous invite à réfléchir sur le "temps» à la lumière de la Constitution et de la culture constitutionnelle. En elle, suivant sa prémisse générale selon laquelle les constitutions sont des textes qui ont un sens juridique et culturel, elle nous rappelle qu'elles nous sont présentées comme des garants de continuité et de changement. Ainsi, l'enseignant Häberle nous enseigne que la Constitution n'est pas seulement un règlement normatif, mais aussi l'expression d'une étape de développement culturel, un moyen d'auto-représentation culturelle d'un peuple, le reflet de son héritage culturel et le fondement de ses espoirs. . Il souligne que l'approche du problème du temps en droit constitutionnel est mise à l'épreuve par rapport à la nécessité de préserver un patrimoine culturel spécifique dans l'intérêt des générations futures. En ce sens, il soutient que la Constitution doit être pensée dès le départ en prenant en compte et en 
assumant la responsabilité de ceux qui sont à venir, «la Constitution d'aujourd'hui porte en elle-même une partie de la Constitution du futur», dit-il. Concrètement, cela nous laissera deux questions ouvertes à cet égard: le respect de l'environnement et les limites de l'endettement de l'État.

Mot-clés: Constitution; Interprétation constitutionnelle;culture constitutionnelle

摘要: 在这项工作中, 著名的德国法学家邀请我们根据宪法和宪法 文化反思 “时间”。在它的基本前提下，宪法是具有法律和文化意义 的文本, 它提醒我们, 宪法是作为连续性和变革的保证人而提出的. 因此, 哈伯勒老师告诉我们, 宪法不仅是一项规范性法规, 而且是文 化发展阶段的表达, 是人民的文化自我代表的手段，反映了他们的 文化遗产和希望的基础. 他指出, 宪法法律中时间问题的处理方法 是针对为了子孙后代的利益而保护特定文化遗产的需要进行检验 的. 从这种意义上说, 他认为应该从一开始就考虑宪法, 并考虑到对 未来的人民负责，他说: “今天的宪法本身就是未来宪法的一部分. ”具体而言, 这将使我们在这方面有两个悬而未决的问题:关心环境 和国家债务的局限性

关键字: 宪法, 宪法解, 宪政文化

\section{Introducción: Dimensión macro - Dimensión micro - Ejemplos de la cotidianeidad}

El intento por abordar el tema del "tiempo" a la luz de la Constitución y la cultura constitucional, comienza con un primer acercamiento a partir de ejemplos cotidianos y de polémicos interrogantes políticos (palabras claves: límites del endeudamiento del Estado, desechos atómicos). La problemática del tiempo se desdobla para la comunidad política en dos dimensiones: la primera, grande e "histórica", puede caracterizarse como "la Constitución en el tiempo". Es la dimensión macro. La segunda dimensión, o "pequeña" dimensión micro, puede ser caracterizada como "el tiempo en el derecho constitucional". En el ámbito macro se analizan las constituciones y su legislación en la historia, en el ámbito micro se aborda el 
tiempo en la actualidad del derecho constitucional concreto, es decir, para nosotros en la Constitución.

Comencemos con ejemplos acerca de cómo vivencia el ciudadano el tiempo en lo jurídico. Hasta el lego se encuentra familiarizado con figuras legales cotidianas referidas al aspecto temporal y pertenecientes a la dimensión micro: plazos, que de no ser cumplidos, conducen a la pérdida de derechos; la prescripción de derechos o de la posibilidad de una persecución penal para salvaguardar la paz jurídica. Los fallos judiciales adquieren validez legal, los actos administrativos de una autoridad pública adquieren vigencia. Algunos padres contemplarán el establecimiento de la mayoría de edad de sus hijos a los 18 años con sentimientos encontrados, de la misma manera percibirán algunos políticos la disminución de la edad para ejercer el derecho al voto. Pensemos también en los períodos legislativos del Parlamento o en los períodos del mandato de los gobernantes como un ejemplo de control y legitimación del poder político en las democracias, lo cual se hizo evidente hace muy poco en la así llamada "des-elección" de Carter y Giscard (1980 y 1981 resp.). ${ }^{3}$ Se podrían señalar gran cantidad de otras formas jurídicas vinculadas a la temporalidad de los acontecimientos cotidianos. En el campo problemático de la protección jurídica, la interrelación entre justicia y temporalidad no se muestra sólo en la discusión acerca de la duración de los procedimientos contencioso-administrativos (por ejemplo,

\footnotetext{
3 El factor tiempo juega un rol diferente según el ámbito de función estatal. El período electoral de 4 años del Parlamento alemán, por ejemplo, se corresponde con su función de órgano parlamentario; sin embargo, la restricción a 12 años de la duración en el cargo de los jueces del Tribunal Constitucional Federal (§ 4 BVerfGG) no resulta lógica, ya que anteriormente eran elegidos para cubrir el cargo con carácter vitalicio. El principio de adjudicar solamente por un tiempo ciertos cargos públicos en diferentes entidades o funciones, se justifica desde muchos aspectos: evitar el abuso de autoridad, legitimación democrática, apertura frente a nuevos desarrollos, etc., y en parte también fortalecimiento de la independencia (judicial): el tiempo y la función (pública) se hallan específicamente vinculados. En sentido inverso, también es válido que un mandato es entregado por un tiempo determinado y debe ser asumido responsablemente por el mandatario, quien sólo debería ser relevado de su cargo anticipadamente en situaciones excepcionales.
} 
en el caso de la solicitud de asilo y en los procedimientos de autorización relativos a la ley de instalaciones nucleares) o en la "protección jurídica provisional" (como en el caso de los procesos de numerus clausus); ya los enormes "lapsos de tiempo" que insumen, por ejemplo, los procesos vinculados al nacionalsocialismo (como el proceso de Majdanek) o en el caso König ${ }^{4}$ demuestran, cómo puede verse afectada la justicia (ya sólo) por una excesiva duración del proceso judicial. ${ }^{5}$

Escritos de conmemoración como "30 años de República Federal - Tradición y cambio" nos recuerdan cuán fuerte es la influencia del tiempo en nuestra acreditada Constitución, ya que en estas tres décadas se sucedieron no menos de 34 modificaciones formales del texto constitucional: la dimensión macro se torna visible. La ciencia del derecho constitucional no se halla sola en este punto: desde un enfoque general, es decir en el aspecto cultural, se "redescubre" la historia. Esto se inicia con los esfuerzos por recuperar para el Liceo un "canon de materias, textos y valores" los estudiantes con relación a la historia constitucional como hacia la búsqueda de una manera de contribuir a la "superación de la ahistoricidad de la democracia alemana" ${ }^{\text {. }}$

4 EuGH Derechos Humanos, NJW 1979, p. 477 ss. Podría haberse decidido "correctamente" a partir del Art. 19, inc. 4, Art. 103, inc. 1 GG. Ver ahora BVerfGE 55, 349 (369): "Una protección legal eficiente también significa una protección legal en un tiempo acorde". Véase también BVerfGE 55, 1 (6): la audiencia judicial evita que "se tomen decisiones apresuradas".

5 Un ejemplo para el trabajo con argumentaciones sobre el tiempo en la determinación del derecho consuetudinario: BVerfGE 34, 293 (304).

6 Título del tomo publicado por J. Becker 1979; además: D. Merten/R. Morsey (Ed.), 30 años de Ley Fundamental, 1979. En revistas especializadas: H. Maier, H. Ridder, U. Matz y A. Grosser, en: PVS 20 (1979), p. 156 ss., 168 ss., 183 ss. también 190 ss.; H. Weichmann, en: DVBI. 1979, p.364 ss.; G. Hartkopf, H. Schnoor y M. Rommel, en: DÖV 1979, p. 349 ss., 355 ss., también 362 ss.

7 Cf. K. Adam, en: FAZ del 15/12/1980, p. 21.

8 P. Glotz, citado en FAZ del 16/12/1980, p. 2 - P. Lerche reflexiona como mentor de una serie de trabajos de la empresa Siemens sobre el tema "La neurosis alemana" (Escritos de la Fundación Carl Friedrich von Siemens, editados por A. Peisl y A. Mohler, tomo 3, 1980, p. 238, 240) acerca de la siguiente idea: Un pueblo recién es capaz de actuar cuando está en condiciones de relatar su historia y de identificarse con ella y a partir de ella. 
Especialmente polémicas son hoy en día dos cuestiones jurídicas, bajo las cuales la problemática del tiempo adquiere una nueva dimensión al basarse en la comprensión de la Constitución como un "contrato generacional": en primer lugar, la protección de las futuras generaciones de los "desechos atómicos"; en segundo lugar, la pregunta acerca del límite del endeudamiento del Estado; ambas cuestiones que deben ser abordadas por el bien de las futuras generaciones. Estos interrogantes tienen varios puntos en común: el texto positivo de la Ley Fundamental (GG) nos abandona aquí. Por ello es preciso argumentar a partir de la interpretación de la Constitución y desde un profundo análisis cultural: Una Constitución entendida como contrato (social) dinámico en el sentido de una "convivencia constantemente resignificada”, ¿no implica también la protección de las futuras generaciones, de sus bienes culturales como sustrato material e inmaterial de su vida, su entorno y su libertad frente a cargas impositivas desmesuradas? El actual intérprete de la Constitución y político también se encontraría entonces ante limitaciones temporales correspondientes a la dimensión macro. A estos interrogantes teóricos podría responder el tema "tiempo y cultura constitucional". Porque la "cultura" remite a responsabilidades y compromisos que un punto de vista puramente jurídico no sería capaz de reconocer.

\section{Evaluación de la situación: El problema del tiempo en la práctica y la teoría constitucional}

\subsection{Puntos de partida de la discusión}

El Estado constitucional de carácter occidental se distingue por reconocer la dignidad humana como premisa, la soberanía del pueblo y la división de poderes, los derechos fundamentales y la tolerancia, la diversidad de partidos políticos y la autonomía de los tribunales; con buenas razones se lo elogia como democracia pluralista, o dicho de otra manera, como sociedad abierta. A su Constitución, entendida como reglamentación jurídica fundamental del Estado $y$ la sociedad, le corresponde una 
vigencia jurídica formal elevada. Ella posibilita un momento de estabilidad y permanencia; un ejemplo impresionante es la Constitución americana con más de 200 años de existencia. Por esta permanencia en el tiempo - en el Art. 79 inc. 3, la Ley Fundamental presenta en defensa de los principios fundamentales y al igual que algunas otras Cartas Magnas, una "pretensión de perpetuidad"! - se tornan necesarios instrumentos y procedimientos, gracias a los cuales la Constitución como "proceso abierto" pueda adaptarse de manera flexible a transformaciones, sin que el sentido de la misma se vea alterado: esto es "estímulo y barrera" en el sentido de $S$. $R$. Smends, y también "norma y tarea" (U. Scheuner) y "limitación y racionalización" del poder estatal (H. Ehmke), pero también del poder social. Justamente la Constitución nacional de los EEUU conoce, a pesar de las numéricamente escasas modificaciones sufridas por la misma en sus 200 años, procedimientos de cambio: especialmente por sentencias de jueces del Tribunal Constitucional.

El derecho público alemán se dedicó más específicamente al tema del tiempo recién en los años 70. Tanto la euforia reformista de esos años como también los jubileos constitucionales y el justificado orgullo por nuestra Ley Fundamental y su historia, podrían haber contribuido a la discusión del tema tiempo. Así hallamos que en 1974 las palabras claves "tiempo y Constitución" 10 , y más tarde su transformación en "Constitución y tiempo"11; las palabras de W. Maibofer acerca de la "ciencia jurídica como ciencia del futuro" (1971) y los estudios

\footnotetext{
9 Véase P. Häberle, Verfassung als öffentlicher Prozess, 1978.

10 P. Häberle, Zeit und Verfassung, en: ZfP 21 (1974), p. 111 ss., ahora en: Ibid., Verfassung als öffentlicher Prozess, 1978, p. 59 ss.

11 Cf. M. Kloepfer, en: Der Staat 13 (1974), p. 457 ss.; W. R. Schenke, en: AöR 103 (1978), p. 566 ss. Más literatura acerca del tema: W. Fiedler, Sozialer Wandel, Verfassungswandel, Rechtsprechung, 1972; G. Dürig, en: FS Tübinger Juristenfakultät, 1977, p. 21 ss. Anteriormente: H. U. Evers, en: W. Weber/C. H. Ule/O. Bachof (ed.), Rechtsschutz im Sozialrecht, 1965, p. 63 ss.; R. Bäumlin, Staat, Recht und Geschichte, 1961, p. 9 ss.; S. Rosenne, The time factor in the Jurisdiction of the Internacional Court of Justice, 1960; K. Engisch, Vom Weltbild des Juristen, $2^{\mathrm{a}}$ edición, 1965, p. 67 ss.
} 
tempranos de G. Husserl sobre "Derecho y tiempo" (1955) fueron tan motivantes como el descubrimiento de la planificación como "nueva" función del Estado. ${ }^{12}$ También el "principio esperanza" de Ernst Bloch podría ser un incentivo permanente para tematizar la dimensión del tiempo en la vida en sociedad y reflejarla concientemente en el derecho. ${ }^{13}$

La mayoría de los trabajos actuales sobre el tema del tiempo se caracterizan por dos cuestiones: en primer lugar, pierden de vista la ambivalencia de Jano con relación al "tiempo": el tiempo se contempla con entusiasmo de descubridor especialmente con vistas al futuro, el aspecto tradicional no es trabajado con la misma profundidad ni de manera diferenciada. Pero como la particularidad del Estado constitucional es el entretejido flexible de momentos dinámicos $y$ estáticos, debe ser posible analizar la tradición y/o la herencia $y$ el presente y/o el futuro, prospectivamente con sinceridad. Aunque cambien los intereses y las necesidades a lo largo de la historia del desarrollo de una Constitución, en la teoría constitucional se deben abordar desde un principio ambas perspectivas. En segundo lugar, el tema del tiempo no es analizado ni en lo metodológico ni conceptualmente más allá de lo estrictamente jurídico: por ejemplo desde un punto de vista cultural amplio, cultura de la cual la Constitución y el derecho no son más que una parte. El nuevo libro de $R$ Wendorff "Tiempo y cultura" de 1980 se convierte por esta razón en un desafío para continuar desarrollando nuestro

\footnotetext{
12 Al respecto ver J. H. Kaiser, en: J. H. Kaiser (ed.), Planung, tomo 1, p. 7, 31 ss.

13 La Utopía, un texto clásico para el estudio de las ciencias del Estado, introduce de manera utópica al futuro directamente en el presente. El futuro cumple una función en el hoy: como esperanza, pero también como alivio del presente. No sería osado decir, que las utopías son indispensables para el pensar y actuar político. Su "élan créateur" es siempre un desafío para el presente y sus posibilidades. ¡También el actual Estado constitucional ha sido alguna vez una utopía! La corriente crítica que vincula las utopías implícita o explícitamente al presente -muchas veces por desplazamiento de espacio y tiempo al plano utópico- es también imprescindible en una sociedad abierta. Es un medio legítimo de crítica a las condiciones vigentes, por más "insoportables" que parezcan las utopías muchas veces. Lo peculiar en este caso es, que la literatura determina aquí con ayuda de una maniobra que desplaza espacio y tiempo, una ciencia básica como la teoría del Estado y la teoría constitucional.
} 
tema "Tiempo y Constitución" de 1974 como "Tiempo y cultura constitucional".

\subsection{Instrumentos del Estado constitucional y procedimientos para la vinculación de la Constitución con el tiempo}

Al comparar diferentes constituciones occidentales, puede observarse que éstas rinden tributo al factor tiempo en dos sentidos:

1) Mirando hacia atrás (retrospectivamente): al pasado, la tradición y la transmisión oral, a los orígenes y a la "herencia cultural".

2) Mirando hacia adelante (prospectivamente): al futuro, lo que será (por ejemplo, en forma de las así llamadas "modificaciones de la Constitución”, cláusulas experimentales legales, efecto anticipado de leyes y de tratados internacionales o modificaciones del texto constitucional).

En el espacio de tensión entre ambas dimensiones, en la interacción entre los procesos más fuertemente tradicionales y los más prospectivos, "vive" la Constitución de las sociedades abiertas, cuya característica distintiva es justamente el reconocimiento de las no simultaneidades del desarrollo de las sociedades (y con esto del pluralismo). A largo plazo se llega, atravesando ambas dimensiones, a procesos culturales de producción y recepción, de los cuales participan las constituciones y a través de ellas todos los intérpretes de una sociedad abierta: funcionarios estatales y públicos, legisladores y partidos, ciudadanos y grupos, la Corte Suprema de justicia y los tribunales inferiores, que son más que los así llamados "tribunales específicos", la teoría del derecho público y también otras ciencias, hasta (y en especial) el arte.

En detalle:

\subsubsection{Vinculación de la Constitución a la tradición y al origen}

Las constituciones no surgen de una tabula rasa ni en una hora cero en lo cultural. Aún si se han originado como resultado de procesos revolucionarios, se reconocen formas de vinculación 
con hallazgos previos, se conservan huellas de la vieja cultura del derecho (constitucional). La Ley Fundamental y desde 1946 las constituciones de los Länder alemanes, conocen instrumentos diferenciados para la incorporación de la tradición y las tradiciones. Su tratamiento debe ser previo a la discusión acerca de la modificación de las constituciones.

\section{a) Cláusulas de recepción y de "herencia cultural"}

En primer lugar se encuentra la recepción explicita (tradición a través de la recepción): ejemplos como el Art. 140 de la Ley Fundamental (la adopción del derecho público eclesiástico de Weimar), pero también cláusulas de la tradición como el Art. 12 inc. 2 de la Ley Fundamental o el Art. 123 inc. 1 de la Ley Fundamental ("las normas jurídicas existentes con anterioridad a la reunión del Parlamento Federal continuarán vigentes, en tanto no se contradigan con lo expresado en la Ley Fundamental") son formas clásicas de recepción en un Estado constitucional. ${ }^{14}$ Por lo demás, existe una cantidad interesante de recepciones más o menos tácitas, especialmente en la parte dogmática. ${ }^{15}$

14 Otros ejemplos: cf. el Art. 178 inc. 2, p.1 e inc. 3 WRV; ver también las reglamentaciones en el Art. 170 inc. 3 p.1, 174 p.1 WRV. Además: el Art. 94 inc. 3 de la Constitución de Baden Württemberg; el Art. 186 incisos 2 y 3 de la Constitución de Baviera; el Art. 85 de la Constitución de Berlín; el Art. 151 inc. 2 de la Constitución de Hessen (modificación de la "unidad jurídica existente" sólo por un motivo inexcusable); el Art. 55 de la Constitución de Niedersachsen; el Art. 137 de la Constitución de Rheinland Pfalz; el Art. 132 de la Constitución de Saar con una cláusula de adaptación. Véase también el Art. 56 inc. 2 de la Constitución de Niedersachsen: "estas instituciones regionales heredadas de los (sc. antiguos) Länder...". De vez en cuando se hacen justamente allí referencias a futuras Constituciones: el Art. 152 de la Constitución de Bremen; véase también el Art. 153 inc. 2 de la Constitución de Hessen: "la legislación futura de la República Alemana prevalece sobre la legislación de los Länder". Además: el Art. 141 de la Constitución de Rheinland Pfalz.

15 Para ello véase P. Häberle: Die Wesensgehaltgarantie des Art. 19 inc. 2 GG, primera edición 1962, p. 162 ss.; véase también P. Lerche, en: ZZP 78 (1965), p. 1 (11 ss.). Si se revisan las Constituciones de los Länder alemanes desde 1946, se hallan cláusulas de recepción referentes al Art. 140 de la Ley Fundamental (como el Art. 5 de la Constitución de Baden Württemberg, el Art. 22 de la Constitución de Nordrhein Westfahlen), acerca de cómo el derecho público eclesiástico en Alemania no es solamente, como lo demuestra el Art. 140 de la Ley Fundamental, una materia "plena de recepción", compárense por ejemplo las garantías de los convenios 


\section{Culturas jurídicas como el derecho del ciudadano, el Código Civil Alemán (BGB), ${ }^{16}$ vivieron de esta manera grandes transfor- maciones constitucionales ${ }^{17}$, a veces por medio de un "salto de recepción" por encima de períodos - como el así llamado "Tercer}

eclesiásticos en el Art. 8 de la Constitución de Baden Württemberg o la garantía de status quo en el Art. 7 inc. 1 (las prestaciones a las iglesias quedan garantizadas); similar es el Art. 145 inc. 1 de la Constitución de Baviera, el Art. 133, inc. 1, párr. 2 de la Constitución de Baviera: "comunidades religiosas reconocidas"; ver también el Art. 37, inc. 2, de la Constitución de Saar; el Art. 60 inc. 2 de la Constitución de Hessen: garantías de status quo para las facultades teológicas de las Universidades. También se encuentran referencias a "prácticas diferentes" (Art. 10 de la Constitución de Baden Württemberg). En todos los sitios en que se hallan referencias a valores culturales cristianos aparece más o menos claramente el aspecto de la recepción, comp. Art. 3 inc. 1, párr. 3, de la Constitución de Baden Württemberg: "tradición cristiana"; Art. 16 inc. 1 de la Constitución de Baden Württemberg: "valores cristianos y occidentales en la formación y la cultura". Ver también BVerfGE 41, 29 (52). También las garantías de los feriados se encuentran bajo la influencia de la tradición, comp. Art. 147 de la Constitución de Baviera: "Los domingos y los feriados oficialmente reconocidos quedan legalmente protegidos como días de introspección espiritual y descanso laboral", de la misma manera ver Art. 53 de la Constitución de Hessen. Significativo es el Art. 3, inc. 1, párr. 2, de la Constitución de Baden Württemberg: "De este modo debe salvaguardarse la tradición cristiana”. Ocasionalmente se extienden las garantías de status quo, por ej., Art. 6, inc.3, de la Constitución de Nordrhein Westfahlen: "La participación de las iglesias y comunidades religiosas, así como también (!) de las asociaciones de beneficencia..., debe garantizarse y promoverse". Pero el $1^{\circ}$ de mayo ha sido alguna vez un feriado "revolucionario" ganado a través de duras luchas. La conservación de monumentos históricos y la protección del paisaje son otros rubros que se encuentran regulados desde un punto de vista tradicional y de recepción, comp. por ej. el Art 141 de la Constitución de Baviera; el Art. 62 de la Constitución de Hessen. Las Constituciones de los Länder alemanes son citados según C. Pestalozza (ed.), $2^{\text {a }}$ edición, 1981.

16 Y en su contexto histórico también el derecho de responsabilidad del estado, cf. con el trabajo reciente de P. Badura, en: NJW 1981, p. 1337 (1339 ss.).

17 De esta manera pueden perder relevancia en el texto constitucional importantes instituciones, ¡hasta pueden desaparecer! Un ejemplo es el principio del carácter público de la jurisprudencia. En el Art. X §178 de la Constitución de la Iglesia de San Pablo aún se puede leer: “El proceso judicial debe ser público y oral". En la Ley Fundamental falta una norma de este tipo (sin embargo véase el Art. 90 de la Constitución de Baviera: jestablece por principio procesos judiciales públicos!). Su contenido debe contemplarse, sin embargo, en el Art. 92 de la Ley Fundamental (algo similar vale para la autonomía municipal programada en el Art. XI §184 íbid. y en el Art. 28, párr. 2, de la Ley Fundamental). En el Art. 109 WRV debía decir además en el párr. 3: "Los privilegios o desventajas jurídico-públicas de nacimiento o de posición social deben abolirse; las denominaciones de los nobles sólo valen como parte del nombre...". En el art. 3 de la ley Fundamental esto se ha presupuesto en forma inmanente. Muchos de los principios mencionados aún individualmente en el art. 129 WRV forman parte ahora de los "principios tradicionales" del servicio público de carrera" según el Art. 33, párr. 5 de la Ley Fundamental. Considerado de esa manera, las constituciones crean de diversas formas una continuidad de la recepción explícita o tácita. 
Reich”. En el medio de la „interpretación histórica“, como el medio clásico de corresponsabilizar jurídicamente al pasado ${ }^{18}$, se constituye así un "cuadro de conjunto previo al derecho constitucional" (H. Nawiasky) $)^{19}$ para su conexión con el pasado ${ }^{20}$. A causa de la naturaleza de nuestro tema de estudio deben considerarse especialmente aquellos principios constitucionales que refieren de manera intensiva a profundas dimensiones de la cultura constitucional. Nos referimos a normas que se remiten a aspectos de la "herencia cultural", plasmadas principalmente en los preámbulos ${ }^{21}$ pero también en otros textos jurídicos ${ }^{22}$.

18 Ver también Ch. Starck, VVDStRL 34 (1976),, p. 43 (72); P. Häberle, Zeit und Verfassung (1974), ahora en: Verfassung als öffentlicher Prozess, 1978, p. 59 (76 ss.).

19 H. Nawiasky, Allgemeine Rechtslehre, 2da. edición, 1984, p. 130 ss.; ver también BVerfGE 56, 22 (28): "Visión general del derecho procesal preconstitucional".

20 No se deben realizar interpretaciones a-temporales para evitar la formación de "fósiles constitucionales"; cf. críticamente W. R. Schenke, AöR 103 (1978), p. 566 (584). Ejemplos de los peligros de estas "petrificaciones" se encuentran fácilmente a partir del análisis de los "principios tradicionales del servicio público de carrera" (Art. 33 inc. 5 GG). Las recepciones de los textos (jurídicos) hallados no son exclusivamente una recepción "pasiva". Los textos incorporados alcanzan en sus nuevos con-textos nuevas dimensiones y contenidos correspondientemente transformados. En sentido inverso, modifican a su vez a estos con-textos. De esta manera, también en este caso tiene lugar una interacción entre recepción (cultural) y producción.

21 Cf. Con el Preámbulo de la Constitución de Hamburgo: „Como ciudad portuaria cosmopolita se le adjudica una misión condicionada por su historia y su ubicación...". Preámbulo de la Constitución de Baviera: "Más de mil años de historia". Quizás la más amplia descripción de la herencia cultural -superadora de lo exclusivamente jurídico- sea la que se encuentra en la Preámbulo de MRK del año 1950: “...decididos, como gobiernos de Estados Europeos que comparten un mismo espíritu y poseen una herencia compartida de bienes espirituales, tradiciones políticas, preservación de la libertad y vigencia de las leyes...". Los preámbulos demuestran ser, además, aquellas partes constitutivas de los textos jurídicos que le otorgan mayor espacio a lo cultural en sentido amplio y que constituyen los puentes entre éste y el texto jurídico más formal. Ya la Constitución del Consejo Europeo del 5/5/1949 establecía puentes entre lo espiritual y los principios jurídicos en su preámbulo: “... en inquebrantable unión entre lo espiritual y los valores, que son la herencia común de sus pueblos y la base de la libertad personal, la libertad política y el dominio del derecho, principios en los que se fundamenta toda democracia real". La Carta Social Europea (CSE) de 1961 invoca ya en su preámbulo los ideales y fundamentos que constituyen la "herencia común" de los integrantes del Consejo Europeo; al mismo también promueve el "desarrollo de los derechos humanos y de las libertades básicas". Para información general ver: P. Häberle: Präambeln im Text und Kontext von Verfassungen, FS Broermann, en prep.

22 Cf. Art. 1 del Convenio Cultural Europeo del 19/12/1954 (citado en F. Berber, Völkerrecht, Dokumentensammlung, tomo 1, 1967): “Cada parte del convenio tomará medidas adecuadas 
b) Textos clásicos y metas educativas

Los textos clásicos y las metas educativas son "canales de transmisión" culturales similarmente efectivos para la tradición.

Textos clásicos como los de Locke y Montesquieu ${ }^{23}$ impulsaron la conformación del Estado constitucional y lo perfeccionaron. Lo que en tiempos de Tomás Moro y aún después había sido una "utopía", es hoy en día el ejercicio cotidiano de las conquistas del Estado constitucional: pensemos en elementos del Estado de derecho, la limitación de la fuerza pública a través del derecho a la resistencia como ultima ratio. En la historia (constitucional) reciente, estos textos clásicos se constituyen siempre de nuevo en objetos de legitimación y de desafío para el Estado constitucional. No solamente los "Federalist Papers" de 1788 para los EE.UU., sino también viejos y nuevos textos (desde Sófocles hasta $B r e c h t$ ) referidos a la dignidad humana ${ }^{24}$, almacenan conocimientos culturales y experiencias que sobreviven al constitucionalista "positivo". Los analistas constitucionales del futuro podrán reinterpretar los textos viejos, ipero no los deberán archivar! A modo de ejemplo quiero recordar, cómo una y otra vez se contraponen las ideas de Montesquieu y Rousseau para facilitar la comprensión de lo que es la democracia en la Ley Fundamental. ${ }^{25}$

En conclusión, las metas educativas explícitas así como aquellas generadas a partir de la interpretación transmiten bienes culturales (según Art. 131 inc. 2, 136 inc. 2, de la Constitución de Baviera, por ejemplo, tolerancia, dignidad humana,

para la preservación y el fortalecimiento de su contribución a la herencia cultural común de Europa". Ver también Art. 5 Ibíd.: "Como parte constituyente de la herencia cultural común de Europa". Todas estas formas de recepción son una parte de la legitimación del presente a partir de la tradición.

23 Detalles con respecto a lo siguiente en: P Häberle, Klassikertexte im Verfassungsleben, 1981, p. 11 ss. 35, 47 ss. De la literatura ver también T. S. Eliot: Was ist ein Klassiker? (1944), 1963.

24 Al respecto ver mi conferencia sobre dignidad humana brindada como profesor invitado en Atenas y publicada en: Rechtstheorie 11 (1980), p. 389 (420s., 423s.).

25 Por ejemplo con relación a los Art.38 a 21 de la GG. 
reconciliación de los pueblos, etc.) y expresan en parte la "herencia cultural". ${ }^{26}$ En este sentido cumplen la función de instrumento para la estabilización de lo previamente hallado y al mismo tiempo se orientan hacia el futuro: fundamentan la sociedad abierta desde lo cultural y más allá de lo jurídico, asegurando así el Estado constitucional para las futuras generaciones. Con la recepción también se puede recibir el cambio: de esta manera, después de los diferentes pasos de superación del pasado, se consideran el presente y el futuro.

\subsubsection{La interpretación del factor tiempo en el presente y el futuro}

Los métodos e instrumentos para la interpretación jurídicoconstitucional del factor tiempo con vistas al presente ${ }^{27}$ y al futuro son variados; una interpretación constitucional más "dinámica"28 adquiere una importancia primordial. Clasificándolos según el grado de formalización, se obtiene el siguiente cuadro:

a) Cláusulas de futuro y progreso

Una forma especial de reivindicación de los textos constitucionales del futuro se encuentra en diversas variantes: en la fijación absoluta, "eterna", de determinados principios - similar al Art. 79 inc. 3 Ley Fundamental ${ }^{29}$-, en la formulación de una

26 Detalles en P. Häberle, Kulturpolitik in der Stadt - ein Verfassungsauftrag, 1979, p. 29 ss.; ibíd. en: FS Hans Huber, 1981; p. 211 ss.; ibíd. en: RdJB 28 (1980), p. 368 ss.

27 No olvidemos que el factor tiempo también remite al presente. En el derecho constitucional esto se denomina "validez", afirmación y aceptación de parte de los intérpretes constitucionales de la sociedad abierta, capacidad de imposición y presencia en la conciencia de la comunidad jurídica. A pesar de ello el "presente" podría ser más bien un tema de gestión, ver P. Kirchhof, Verwalten und Zeit. Acerca de una gestión referida al presente, en plazos temporales adecuados y no anacrónicos, 1975, en especial p. 2 ss., con referencia a G. Husserl, Recht und Zeit, 1955, p. 42 ss., 52 ss.

28 Cf. con un enfoque de orientación más "estática": W. Leisner, en: Der Staat 7 (1968), p. 137 ss.

29 Cf. Art. 16 Decl. 1789; Art. 110 inc. 1 de la Constitución de Grecia (1975); Art. 130 de la Constitución de Bélgica; Art. 9 de la Constitución de Turquía (1961); Art. 89 inc. 5 de la Constitución de Francia (1958); Art. 75 inc. 1, párr. 2, de la Constitución de Baviera (1946). 
"pretensión de validez ${ }^{30}$ para siempre vigente", o en la negación permanente de situaciones legales antiguas especialmente reprobables, como la servidumbre y el título. ${ }^{31}$ La profunda superación del pasado se convierte aquí en grandes pretensiones para el futuro. Otra tematización del futuro se halla en constituciones que hablan explícitamente de un "futuro prometedor"32 y que se dirigen a las futuras generaciones alemanas ${ }^{33}$, que exigen a la República el estímulo al desarrollo cultural ${ }^{34}$ o que invocan el "progreso": en cláusulas, que se expresan en la garantía del feriado del $1^{\circ}$ de mayo como manifestaciones a favor del progreso (Art. 32 de la Constitución de Hessen 1946) o en un sentido aún más amplio. ${ }^{35}$ Los dos aspectos de una cultura, el tradicional como el prospectivo, se expresan aquí claramente. ${ }^{36}$

b) Cambios constitucionales en virtud de la interpretación constitucional

De manera relativamente disimulada y sin formalización alguna tiene lugar la transformación de la Constitución ${ }^{37}$ en virtud

30 Es el caso del Art. 25 inc. 2, de la Constitución de Grecia (1975): "derechos humanos sempiternos".

31 "La servidumbre quedará suspendida por siempre": § 25 de la Constitución de Baden Württemberg (1819); similar es el Art. IX §166 de la Constitución de la Iglesia de San Pablo; Art. II § 137 lbíd.: "Todos los títulos...quedarán suspendidos y no podrán ser introducidos nunca más". Art. 186 inc. 1 de la Constitución de Baviera (1946): "La Constitución de Baviera del 14 de agosto de 1919 es (!) abolida".

32 Preámbulo de la Constitución de Hessen (1831); ver también el "futuro" en el preámbulo de la Constitución de Hessen (1946).

33 Como la orientación generacional del preámbulo de la Constitución de Baviera (1946).

34 Art. 9, inc. 1 de la Constitución de Italia (1947).

35 Preámbulo de la Constitución de España (1978): "Fomentar el desarrollo de la economía y la cultura". Ver también Art. 41 inc. 2 de la Constitución de Turquía. Referencias a futuras constituciones son casos especiales: Art. 152 Bremen; 153 inc. 2, Hessen; 141 Rheinland Pfalz.

36 Significativo es el Art. 9 de la Constitución de Italia: La República fomenta el desarrollo cultural (inc. 1), protege el paisaje y la herencia histórica y artística de la Nación (inc. 2). Los textos son citados según P. C. Mayer Tasch, Die Verfassungen der nichtkommunistischen Staaten Europas, $2^{a}$ edición 1975, según E. R. Huber, Dokumente zur deutschen Verfassungsgeschichte, tomo 1, 1961, y también según C. Pestalozza (ed.), Verfassungen der deutschen Bundesländer, $2^{a}$ edcición 1981. 
de la interpretación, es decir sin modificaciones explícitas del texto. Sólo por medio de la interpretación, ya sea a través de los tribunales, de las acciones del Estado, de la opinión pública y la ciencia, o de la interrelación de todo en su conjunto, se alcanza una comprensión nueva o diferente de la norma constitucional. La propiedad, por ejemplo también la del BGB de 1900, se ve expuesta así a un profundo cambio. ${ }^{38}$ Esto comprende procesos de crecimiento, que con enormes resultados influenciaron principios constitucionales. Por ello, ya tienen muy poco en común la idea de Estado social de 1981 con, por ejemplo, la interpretación de la Ley Fundamental de 1949. También los siempre actuales $^{39}$ logros jurídicos que el BVerfG de 1960 obtuvo en la sentencia con respecto a la televisión, con referencia al Art. 5 de la Ley Fundamental ${ }^{40}$, brindan un ejemplo de transformación a partir de la interpretación. ${ }^{41}$ Los límites -como el límite del texto- son ampliamente discutidos ${ }^{42}$ pero difíciles de establecer.

La interpretación constitucional es, según el método, en sí misma tanto retrospectiva ${ }^{43}$ como prospectiva. ¡Los distintos métodos de interpretación no "organizan" otra cosa que

37 El autor utiliza aquí el término "transformación de la Constitución" aunque, según su punto de vista, este término en realidad debería ser "descartado": Cf. P. Häberle, Zeit und Verfassung (1974), en: Ibíd., Verfassung als öffentlicher Prozess, 1978, p. 59 (82 ss.). De la literatura referente al tema véase P. Lerche, en. Festgabe für Maunz, 1971, p. 285 ss.; K. Hesse, en: FS für Scheuner , 1973, p. 123 ss.; W. R. Schenke, en: AöR 103 (1978), p. 566 (585 ss.).

38 Por último: T. Maunz, en: BayVBI. 1981, p. 311 ss. Sobre los problemas de la dimensión micro trabaja también C. Timm, Eigentumsgarantie und Zeitablauf, 1977.

39 Cf. ahora nuevamente la decisión del BVerfG con relación a la ley de radio y televisión privada (BVerfGE 57, 295).

40 BVerfGE 12, 205.

41 La literatura jurídica acerca de la transformación es casi inabarcable, cf. por ejemplo, J. Harenburg/A. Podlech/B. Schlink (ed.), Rechtlicher Wandel durch richterliche Entscheidung, 1980; W. Finkentscher/H. Franke/O. Köhler (ed.) Entstehung und Wandel rechtlicher Traditionen, 1980; U. Immenga (ed.), Rechtswissenschaft und Rechtsentwicklung, 1980; cf. también el Dictum de T. W. Adorno: „En la cumbre de la ola de lo nuevo es donde se refugia lo antiguo, pero en su ruptura, no en su continuidad".

42 Comp. K. Hesse, en: FS U. Scheuner, 1973, p. 123 (136 ss.).

43 El BVerfG es en este sentido un "órgano de recepción" junto al que se encuentran quienes participan de la interpretación constitucional. 
el tiempo! La interpretación histórica analiza el momento de la creación, la interpretación objetiva analiza el presente y la prognóstica el futuro. Quizás sea la imprevisibilidad general de los períodos temporales la razón por la cual hasta el momento ningún estudio metodológico haya podido atribuir la debida importancia a cada uno de los métodos de interpretación. Probablemente sea su relación mutua una función del tiempo, o sea flexible. Lo que "en general" significan las cláusulas de recepción por un lado y las modificaciones constitucionales por el otro - ya que transmiten la herencia y se dirigen al futuro-, es organizado por los métodos de interpretación "en particular". Por supuesto, la interpretación constitucional difícilmente se ocupe sólo de la herencia o sólo del futuro. La relación mixta de los momentos tradicionales, actuales y futuros debería ser a su vez variable. La interpretación constitucional -comprendida "creativamente" como expresión de la (public) law in action en el sentido de Esser ${ }^{44}$ - se encuentra "tensada" de esta manera en el tiempo.

Si el BVerfG da lugar de manera jurídicamente funcional a las decisiones de prognosis de otras instancias estatales, en especial las del legislador, ${ }^{45}$ es esta una forma de superación interpretativa del tiempo: una porción de futuro ya es tenida en cuenta ahora. Sin duda cada función estatal posee una porción de la competencia prognóstica. En la democracia le corresponde al legislador parlamentario el "primer paso", pero no el monopolio. Finalmente podemos mencionar -estrechamente vinculado con lo anterior- la interpretación organizada por resultados como tributo al tiempo. Las modificaciones de la jurisprudencia son asimismo expresiones de la dimensión micro del "tiempo en el derecho constitucional" y también lo es la retroactividad de las leyes.

\footnotetext{
44 J. Esser, Grundsatz und Norm in der richterlichen Fortbildung des Privatrechts, 1956, ha expresado de manera clásica la interpretación jurídica como suceso en el tiempo.

45 Ver F. Ossenbühl, en: Festgabe 25 Jahre BVerfG, tomo 1, 1976, p. 458 ss. Ver por ejemplo BverfGE 50, 290 (331 ss.); 56, 54 (78 y s).
} 
c) Votos en disidencia

El voto en disidencia (Sondervotum) emitido por jueces constitucionales que realizan interpretaciones alternativas puede constituirse en una forma especial de anunciación y de promoción, hasta de aceleración de la "reforma constitucional". En especial la historia de la jurisdicción constitucional en los EEUU ofrece ejemplos asombrosos ${ }^{46}$, como en lo relativo a la legislación del New Deal de Roosevelt. También en nuestro caso ya se pueden hallar indicios de los efectos de la "jurisprudencia alternativa" a partir de votos en disidencia sobre el desarrollo de las sentencias del BVerfG. ${ }^{47}$

Considerado en el tiempo, existen dos tipos de votos en disidencia: los retrospectivos y los prospectivos. Los votos en disidencia prospectivos son, en general, más espectaculares, porque les pertenece el futuro o al menos pareciera pertenecerles: a través de nuevas interpretaciones se distancian de lo sucedido, de lo hasta el momento reinante y a partir de nuevos descubrimientos ponen "productivamente" en cuestión el consenso establecido en el presente. Un ejemplo es el voto en disidencia de Rupp von Brünneck en lo relativo a las características del carácter de propiedad de la prestaciones sociales ${ }^{48}$, que ahora fue adoptado en su conjunto por el BVerfG para el derecho jubilatorio ${ }^{49}$, recientemente también el voto en disidencia de Simon/Heußner en lo concerniente al caso Mühlheim-Kärlich, que toma nuevas orientaciones surgidas en el ámbito científico y repiensa consecuentemente la cuestión del voto mayoritario..$^{50}$

\footnotetext{
46 Ver W. Haller, Supreme Court und Politik in den USA, 1972 (compárese también mi comentario en BVDI. 1973, p. 388 ss.).

47 Pruebas de ello se encontrarán en P. Häberle, Kommentierte Verfassungsrechtsprechung, 1979, p. 24 ss.; una lista de los votos en disidencia se hallará en B. Zierlein, en: DÖV 1981, p. 83 (94 ss.).

48 BVerfGE 32, 129 (141 ss.)

49 BVerfGE 53, 257 (289 ss.)

50 BVerfGE 53, 30 y 69; pero también K. Redeker, en: NJW 1980, p. 1593 ss. Como otro ejemplo "prospectivo" puede mencionarse el voto en disidencia de dos jueces del BayVfGH
} 
El voto en disidencia de Erwin Stein en el caso Mefisto ${ }^{51}$ podría en este sentido convertirse en un voto en disidencia "prospectivo" y "productivo", especialmente a partir de la reedición del libro de Klaus Mann en la Alemania de nuestros tiempos. El derecho personal de G. Gründgens pierde trascendencia, ya sea por anacrónico o como corrección de la opinión de la mayoría del senado. El límite entre lo legal y lo ilegal puede variar justamente a causa de la aparición de un voto en disidencia. ${ }^{52}$ La fuerza normativa de los votos en disidencia y su rol como "jurisprudencia alternativa" son especialmente visibles en este ejemplo, así como también lo es el proceso de producción y recepción que supera el aspecto puramente jurídico: la vitalidad de los procesos culturales se torna efectiva.

Los votos en disidencia retrospectivos expresan una opinión, justificación o resultado que ha sido sobrepasado, o mejor dicho "superado" ("overruled") por los más "modernos" de la mayoría. Simplificando: el punto de vista "conservador" ha quedado reducido a la minoría. ${ }^{53}$ Visto en contexto, es posible que a lo

en cuanto a la aplicación del Art. 141, inc. 3 p. 1 (acceso libre a las bellezas naturales) también para jinetes (BayVfGHE 28 (1975), 107, 135). Aunque la argumentación de este voto en disidencia pareciera ser retrospectiva en la primera parte -se remite a la voluntad del legislador constitucional y la jurisprudencia-, cobra mayor importancia la posterior argumentación que contempla desarrollos futuros y novedosos. Justamente por el gran incremento en la cantidad de jinetes se torna una medida con vistas al futuro el hecho de tomar en consideración los prejuicios hacia ellos expresados en el interés de terceros y el punto de vista de la tolerancia social, para no incluir a los jinetes en el ámbito de aplicación del Art. 141, inc. 3 p. 1 BV (diferente es la opinión de la mayoría en BayVfGHE 28 (1975), 107, también en E 30 (1977), 152).

51 BVerfGE 30, 173, SV 200.

52 El voto en disidencia de Erwin Stein debe haberse interpretado más bien como palabra de aliento por aquellos que creían poder asumir la responsabilidad de una reedición de la novela de Klaus Mann en la República Federal de Alemania, cf. B. Spangenberg, Prefacio para: K. Mann, Mefisto, 1980, p. II, IV; M. Reich-Raniki, FAZ del 18/12/1980, p. 23; B. Spangenberg, Karriere eines Romans, 1981.

53 Sería interesante revisar, si en la relativamente joven historia del voto en disidencia en el BVerfG ya existen ejemplos para ello (probablemente sean más productivos los EEUU). Una justificación más bien retrospectiva (para "bienestar de la mayoría", "interés público", etc.) puede leerse en: SV Böhmer (NJW 1981, p. 1258 ss.) con relación a la cuestión de los teleféricos; cf. también el voto en disidencia de Schlabrendorff, BVerfGE 33, 35 ss. También 
largo del tiempo los votos en disidencia representen una direccionalidad (marginal) muy específica, que corresponde a una parte del espectro total de la República y de la sociedad abierta de sus intérpretes constitucionales. Detrás de la continuidad personal se torna visible la continuidad de la causa, más allá de los senados individuales. De esta manera los votos en disidencia pueden, en pocos años, sustentar tradiciones y en un futuro ganar la mayoría a su favor - o por el contrario, no lograr el consenso ni a largo plazo y convertirse en nota a pie de página de la historia de la jurisprudencia.

\section{d) Legislación (Mandatos legislativos)}

La tarea del legislador puede comprenderse como un permanente análisis del cambio social en el tiempo y nos brinda una gran cantidad de procedimientos y técnicas especializadas. En los inicios de la Ley Fundamental se trataba de "hacer realidad" los mandatos constitucionales abiertos (u ocultos), como por ejemplo la igualdad de derechos de ambos sexos (Art. 3 inc. 2 GG), de los niños concebidos fuera del matrimonio (Art. 6 inc. 5 GG) o también de la democracia en el interior de los partidos (Art. 21 inc. 3 GG) ${ }^{54}$ (cf. también Art. 95 inc. 3, 117 inc. 2 GG); hoy en día son habitualmente mandatos del Tribunal Constitucional Federal logrados a partir de la interpretación, los que obligan al poder legislativo a llegar, en el futuro, a conclusiones (más) acordes al texto constitucional ${ }^{55}$ : ya sea el caso de una normativa declarada como "aún no" (pero pronto) contraria al texto constitucional -como en la reforma de la pensión por viudez, que debe ser efectuada antes de $1984^{56}$ - ya sea que una normativa se

\footnotetext{
debería investigarse si y cómo se podría reconocer el momento prospectivo y el retrospectivo en los métodos de interpretación de cada uno de los votos en disidencia.

54 Pero compárese también A. Arndt, Das nicht erfüllte Grundgesetz, 1960, ahora en: Ibíd., Gesammelte juristische Schriften, 1976, p. 141 ss.

55 Cf. también C. Pestalozza, en: Festagabe 25 Jahre Bundesverfassungsgericht, 1976, tomo I, p. 519 (540 ss., 558 ss.).

56 Cf. BVerfGE 39, 169 (194 ss.)
} 
declare como desfavorable, pero que al legislador se le otorgue un tiempo considerable para su reforma. ${ }^{57}$ El debate acerca de los mandatos constitucionales ${ }^{58}$, o sea, la interpretación de la Ley Fundamental y de sus principios básicos como "mandatos constitucionales", es una tematización del tiempo más o menos consciente que se introduce en los nuevos desarrollos. La teoría del derecho político de Weimar - como era característico - había dejado en suspenso los mandatos legislativos ante la alternativa: ¿declaración programática o derecho actual? ${ }^{59}$

También sin este tipo de mandatos, el poder legislativo concretiza a través de la legislación simple en forma constante y siempre novedosa las libertades fundamentales y los principios de derecho de la Ley Fundamental ${ }^{60}$ y con acentos políticos jurídicos cambiados actúa "desde abajo" sobre la Constitución como proceso abierto. Aquí se enfrenta también al cúmulo de problemas de la dimensión micro del "tiempo en el derecho constitucional" ${ }^{61}$ : desde los plazos en el proceso legislativo relativo a interrogantes acerca del inicio de la vigencia o la duración de la vigencia de una normativa (como uno de los factores de

57 EL Tribunal Constitucional Federal austriaco compromete al legislador en ocasiones y según su disponibilidad temporal a una reforma legislativa gradual.

58 P. Lerche, en: AöR 90 (1965), p. 341 ss.; E. Wienholtz, Normative Verfassung und Gesetzgebung, 1968, ibíd. p. 3 ss. De la jurisprudencia del BVerfG. Existen materias, que a lo largo del tiempo siempre han constituido una tarea para el futuro - durante mucho tiempo fue ésta la situación en la que se encontraba la equiparación del hijo ilegítimo en mandatos constitucionales como en el Art. 121 WRV, y 6, inc. 5 GG. El Estado constitucional muchas veces precisa el trabajo y el compromiso de muchas generaciones. La protección de los monumentos y de la naturaleza son una tarea vigente desde hace ya mucho tiempo, respaldada en la tradición, pero expuesta a una intensificación en el futuro.

59 Para ello ver E. Wienholtz, ibíd., p. 14 ss. El Art. 29 GG, antes un mandato constitucional, ha sido rebajado por la modificación de la Constitución (1975) a una simple norma de competencia. De manera inversa también pueden transformarse las simples normas de competencia en mandatos constitucionales. El Art. 3 de la Constitución de Baviera debe comprenderse como una norma verdadera y teórica, que va adquiriendo la dimensión de un mandato constitucional.

60 Cf. P. Häberle, Die Wesensgehaltgarantie des Art. 19 Abs. 2 GG, $1^{\text {a }}$ edición 1962, p. 219 ss. ; W. R. Schenke, en: AöR 103 (1981), p. 566 (586).

61 Cf. M. Kloepfer, en: Der Staat 13 (1974), p. 457 ss. 
igualación más importantes ${ }^{62}$ ), de los plazos límites o del derecho transitorio, hasta la retroactividad de las leyes, también de las remisiones "dinámicas". ${ }^{63}$ Figuras constitucionales dogmáticas como la protección de la confianza y la lealtad al Estado, también la figura de la protección dinámica del Derecho Fundamental $^{64}$, ocultan problemas (también) de justicia temporal. ${ }^{65}$

\section{e) Efecto anticipado de las leyes}

\section{Solo de manera muy breve serán mencionadas dos formas de incorporación del tiempo en el desarrollo constitucional que han adquirido mayor importancia hace muy poco: en primer}

62 G. Dürig, en: FS Tübinger Juristenfakultät, 1977, p. 21 (29); véase también G. Dürig en: T. Maunz/G. Dürig/R. Herzog/R. Scholz, GG, Kommentar, 5a edición 1980, Art. 3 Inc. 1 GG/ Rdn. 194 ss. Comp. como ejemplo actual BVerfG JZ 1981, p. 60: El legislador debe reglamentar nuevamente las regulaciones legales que el BVerfG ha declarado como incompatibles con el Art. 3 inc. 1 GG de manera tal que también apelen al pasado.

63 La problemática del tiempo también se encuentra en la técnica judicial de la remisión en las leyes, o sea de la referencia a otras reglamentaciones ("objetos de remisión"), por ejemplo, otras normas, prescripciones administrativas, normas DIN, reglamentaciones de asociaciones privadas), mientras se trate de remisiones "dinámicas" (o "anticipatorias") (terminología: F. Ossenbühl, en: DVBI. 1967, p. 401). Éstas no se refieren, a diferencia de las remisiones "estáticas", a la versión vigente en el momento de la aprobación de la norma de remisión, sino a la versión correspondiente de los objetos de remisión. Como éstas son actualizadas con mayor frecuencia y más fácilmente que las leyes, estas últimas se vuelven más "abiertas con el tiempo" por medio de las remisiones dinámicas. El nuevo estado de desarrollo en cada caso se introduce en la ley. Se mantiene de este modo dinámica, pero por otro lado también más dependiente del objeto de remisión y sus creadores. La técnica de la remisión enfrenta por eso también reparos de derecho constitucional (cf. al respecto BVerfGE 47, 285 (311 ss.); 26, 338 (366 s.) con otras referencias; VG Hamburg, NJW 1979, p. 667 ss.; F. Ossenbühl, en la ref. indicada; H.-U. Karpen, Die Verweisung als Mittel der Gesetzgebungstechnik, 1979, p. 101 ss.; íd., en: J. Rödig (ed.), Studien zu einer Theorie der Gesetzgebung, 1976, p. 221 (232 ss.); J.-F. Staats, en: J. Rödig (ed.), en la ref. indicada, p. 244 ss.; íd., en: ZRP 1978, p. 59 ss.; E. Baden, en: NJW 1979, p. 623 ss.; W.-R. Schenke, en: NJW 1980, p. 743 ss.). Menos problemáticas con respecto al derecho constitucional son las posibilidades equivalentes funcionales (por ej., cláusulas generales, prescindencia de determinaciones detalladas, poderes de disposición).

64 Cf. BVerfGE 49, 89 (137).

65 Ver también la cláusula temporal en § 40 BVerfGG. La ausencia de una "cláusula de reincorporación" en el procedimiento para la proscripción de partidos políticos trae problemas importantes. Para ello consultar R. Schuster, en: ZRP 1968, p. 413 ss.; JZ 1968, p. 152 ss. 
lugar el efecto anticipado de leyes y contratos. ${ }^{66} \mathrm{El}$ efecto anticipado de leyes formalmente aún no vigentes es tan demostrable como diferenciadamente admisible. En el ámbito internacional llama la atención el efecto anticipado del contrato SALT II: los EE.UU. y la URSS se atienen aún hoy (más precisamente: mayo 1981) silenciosamente a la letra del contrato. Los efectos anticipados no son otra cosa que la aceleración del factor tiempo.

f) Cláusulas de experimentación y de experiencia

Finalmente consideraremos las cláusulas jurídicas de experimentación y de experiencia. Éstas aparecen especialmente en tiempos de reformas y demuestran ser una puesta a prueba de una temporalmente acotada y limitada anticipación del futuro. En los años 70 fueron tema de discusión central entre nosotros. Un ejemplo conocido es el $\S 5$ b DRiG - la formación jurídica en una sola etapa, a la cual debo, por ejemplo, mi presencia en Baviera, en Bayreuth. No es posible discutir aquí una a una estas cláusulas ${ }^{67}$ ya descubiertas por Montesquieu $^{68}$, pero pueden ser tomadas en cuenta como una forma de "puesta a prueba" de la anticipación del futuro. Hoy en día el interés de la evaluación de las leyes está puesto en: la investigación de la implementación de leyes, por ejemplo, trata a leyes enteras como si fueran un experimento, para poder preparar probablemente enmiendas de leyes perfeccionadoras (en especial en lo relativo al medio ambiente y al derecho de planificación) $)^{69}$; la "legislación a término" se vuelve un tema de interés ${ }^{70}$.

\footnotetext{
66 En cuanto al efecto anticipado de las leyes véase M. Kloepfer, Vorwirkung von Gesetzen, 1974; P. Häberle, Öffentliches Interesse als juristisches Problem, 1970, p. 396 nota al pie 148, p. 486 ss.; ídem., Zeit und Verfassung (1974), en: ídem, Verfassung als öffentlicher Prozess, 1978, p. 59 (83 ss.).

67 Cf. Montesquieu, El espíritu de las leyes, libro II, $2^{0}$ capítulo (Reclam 1976, p. 109).

68 Cf. Véase P. Häberle, Verfassung als öffentlicher Prozess, 1978, p. 85 ss.; véase también D. Pirson, en: FS Jahrreis, 1974, p. 181 ss. Con referencia a la legislación como experimento en el ámbito de "proyectos piloto": W. Schmitt Glaeser, Kabelkommunikation und Verfassung, 1979, p. 205, 207 ss.Montesquieu, El espíritu de las leyes, libro II, $2^{0}$ capítulo (Reclam 1976, p. 109)
} 
g) Reformas constitucionales

El clásico instituto para dar a lo nuevo formalmente y de manera inmediata cabida en el texto constitucional es la reforma constitucional, o sea la modificación del texto constitucional a través de determinados procedimientos, en general con la mayoría calificada como base del consenso (cf. Art. 79 inc. 2 GG). Todos los Estados constitucionales con cartas fundamentales conocen esta posibilidad de dar cuenta del paso del tiempo también en el texto, aunque las condiciones previas (como el tamaño de la mayoría) se diferencian de caso a caso.

Las reformas constitucionales pueden servir para la adaptación a desarrollos que fácticamente ya han tenido lugar; pero también pueden estimular (intencionalmente) estos desarrollos. La modificación a partir de la "adaptación" y de la "configuración" debe ser comprendida de manera diferenciada. La duración y la estabilidad de una Constitución parecieran hablar, en principio, en contra de una reforma constitucional, pero estas reformas justamente pueden servir también a la duración y a la estabilidad de un Estado cuando son "acordes a su tiempo". Si esto es así, sólo puede establecerse caso por caso y según los ámbitos específicos de los que se trate. ${ }^{71}$

Esto vale especialmente para el conjunto de modificaciones constitucionales que deben conducir a la "revisión total" de la Constitución. La discusión alemana en, y acerca de, la Comisión "Enquête" del Parlamento alemán evidentemente ha

\footnotetext{
69 Cf. R. Mayntz (ed.), Implementation politischer Programme, 1980; H. Wollmann (ed.), Politik im Dickicht der Bürokratie, 1980; E. Blankenberg/K. Lenk (ed.), con la colaboración de R. Rogowski, Organisation und Recht, 1980.

70 W. Hugger, en: PVS 20 (1979), p. 202 ss.; véase también K. Eckel, en: ZfS 7 (1978), p. 39 ss.; K. Hopt, en: JZ 1972, p. 65 (70).

71 Para más detalles ver P. Häberle, Verfassung als öffentlicher Prozess, 1978, p. 88 ss. Véase también la limitación temporal para las modificaciones de la Constitución en el Art.110 inc.6 de la Constitución de Grecia (1975): Una reforma constitucional antes de haber transcurrido 5 años de la precedente, es inadmisible.
} 
demostrado ser inadecuada temporalmente ${ }^{72}$ : desde un punto de vista de política constitucional y científico puede decirse que se ha ido diluyendo. En comparación, la más productiva discusión suiza ${ }^{73}$ podría mostrarse más eficiente en el mediano y largo plazo.

Esta evaluación de la situación objetiva relativiza la división analítica entre las dimensiones macro y micro: ambos planos se encuentran relacionados en muchos aspectos. La sumatoria de pequeñas unidades temporales en los procedimientos específicos y los instrumentos de una Constitución conforman en última instancia una parte de la histórica dimensión macro del tiempo. (La interpretación de la Constitución finalmente puede convertirse en una reforma de la Constitución, y ésta en una parte de legislación constitucional!). En sentido inverso también resulta válido decir que la dimensión macro "Constitución en el tiempo" influye en la dimensión micro "el tiempo en el derecho constitucional". Probablemente la transformación de la función del juez, especialmente del juez constitucional, es un cambio significativo: el reconocimiento de votos en disidencia y el efecto anticipado de las leyes, etc., contienen una relajación de la sujeción a la ley y en este sentido también a su duración relativa. La "emancipación" judicial de la ley, que se encuentra en la adquisición de funciones pretorianas, refleja una situación cambiada en el ámbito micro: también el juez, no sólo el legislador (re)acciona ante el cambio: ijusticia hoy, aquí y ahora!

\section{Incursus I: “30 años de Ley Fundamental”}

Por más que los diferentes momentos temporalmente abiertos de una Constitución parezcan independientes, pensados en espacios temporales más grandes, actúan conjuntamente.

\footnotetext{
72 Ver: Enquête-Kommission, Verfassungsreform, Schlußbericht 1976 (BT-Drs. 7/5924); además: R. Grawert, en: Der Staat 18 (1979), p. 229 ss.; R. Wahl, en: AöR 103 (1978), p. 477 ss.

73 Compárese con el diseño de una Constitución Federal Suiza (1977), publicada en: AöR 104 (1979), p. 475 ss.; además: P. Saladin, en: AöR 104 (1979), p. 145 ss.; así como también los trabajos en: ZSR N. F. 97 (1978), $1^{0}$ parte del tomo I, p. 229 ss.; y por último K. Eichenberger, en: ZaöRV 40 (1980), p. 477 ss.; G. Müller, en: Der Staat 20 (1981), p. 83 ss.
} 
La cuestión "30 años de Ley Fundamental" - como sumatoria de las dimensiones micro y macro- exige por un lado, rastrear los temas que con "el paso del tiempo" llevaron a que la Ley Fundamental de 1979 coincida sólo parcialmente con la Ley Fundamental de 1949. Yo lo denomino comprensión constitucional cambiada, estatalidad de la producción, derechos de participación materiales y procesales, la construcción de un Estado social, pero también las variadas modificaciones en la estructura del Estado Federal; no menos importante es la transformada auto comprensión de nuestra República en camino de un simple "Estado provisorio" a un "Estado pleno", pero también su integración en la Unión Europea ${ }^{74}$ y otras formas de cooperación internacional. ${ }^{75}$

Si nos preguntamos también acerca de otras formas y procedimientos a través de los cuales la Ley Fundamental supo reaccionar ante las exigencias y necesidades del tiempo y acerca de los "(pro)motores" de este cambio, nos encontramos con todos los instrumentos y "órganos" para la interpretación del tiempo, o mejor dicho del cambio, arriba mencionados: un lugar central ocupa ya la ("simple") interpretación constitucional, en especial la del BVerfG. Pensemos en la ampliación de los derechos fundamentales bajo las palabras claves sentencia del caso Lüth, sentencia sobre las farmacias, sentencia sobre la televisión, finalmente, por ejemplo, la decisión sobre Mülheim-Kärlich conjuntamente con el voto en disidencia Simon/ Heußner. ${ }^{76}$ La sentencia sobre la televisión con su postulado pluralista fue adoptada expresamente en Baviera a través de una reforma constitucional formal del Art. 111a (1973). ${ }^{77}$ Mucho

\footnotetext{
74 Compárese también los votos de H. F. Zacher y P. Badura referentes a "30 años de Ley Fundamental en Alemania", en: VVDStRL 38 (1980), p. 153 ss., también 156 ss.

75 Sobre el "Estado constitucional cooperativo" consultar mi trabajo con el mismo título (Kooperativer Verfassungsstaat) en: FS Schelsky (1978), p. 141 ss.

76 BVerfGE 7, 198; 7, 377, también 12, 205 y E 53, 30, también 69.

77 En torno a estos dilemas: W. Schmitt Glaeser, Kabelkommunikation und Verfassung, 1979, en especial p. 85 ss.
} 
de aquello que el constitucionalista de 1949 había querido dejar sentado en la Ley Fundamental, fue precisado y profundizado por los intérpretes constitucionales de los siguientes 30 años, pero en gran parte también modificado y transformado; es en este sentido que el análisis "histórico" pierde peso. En esta historia de la interpretación casi se torna posible vislumbrar cuestiones de legislación constitucional. ${ }^{78} \mathrm{Si}$ tomamos las grandes sentencias "pretorianas" del BVerfG y el comentario de esta jurisprudencia a través de la ciencia, entonces reconocemos el profundo cambio a través de la interpretación, pero también los "protagonistas" de esta transformación: en especial el BVerfG, eventualmente preparado por los descubrimientos de maestros del derecho público - "lealtad al estado federal" de $R$. Smend, "preformación de la voluntad política" de U. Scheuner, la "concordancia práctica" de $K$. Hesse o la "compensación considerada" de P. Lerche. ${ }^{79}$ Los alcances de los votos en disidencia en cuanto al anuncio de transformaciones venideras, es decir las interpretaciones alternativas en la última década, no deben ser subestimadas.

De estos procesos también participa el (simple) legislador como precursor del cambio constitucional. Este es el caso en la interpretación de cláusulas de propiedad y del Estado social. Modificaciones de la idea de justicia, tangibles en la decisión conjunta en la empresa, la actualización del principio de igualdad, la igualdad de oportunidades en el ámbito de la formación (de "Honnef" sobre la Bafög [Ley Federal de promoción para la realización de estudios superiores]) y en el desarrollo del derecho laboral y social, no dejan de tener efectos en el largo plazo para el estudio de la Constitución.

El cuadro se completa con la no justamente escasa cantidad de modificaciones constitucionales. Desde la primera, referente

78 Para ello ver mi clase impartida como profesor invitado en Berna "Verfassungsinterpretation und Verfassungsgebung" (1978), publicada en: P. Häberle, Verfassung als öffentlicher Prozess, 1978, p. 182 ss.

79 Cf. BVerfGE 12, 205 (254) y 8, 104 (113), también E 41, 29 (51) y 41, 88 (109). 
a la disminución de rango del Art. penal 143 de la Ley Fundamental acerca de la "alta traición" al plano del derecho común del Código Penal Alemán (StGB), hasta la reciente ampliación de las competencias del Estado Federal (Art. 74 No. 4a GG), puede observarse cómo paso a paso las modificaciones formales de la Constitución en el plano del "tiempo en el derecho constitucional", han conducido al perfeccionamiento y consolidación de la ya no "provisoria" Ley Fundamental y de esta manera a la "normalización" de la Constitución en el tiempo: la Constitución de las Fuerzas Armadas (1956), la Constitución del Estado de emergencia (1968) y la Constitución económica y financiera (1967/69) son "estaciones".

Solamente abordaré el desarrollo de la estatalidad del Estado Federal: aquí se llevaron adelante relativamente muchas transformaciones y modificaciones constitucionales - tendencialmente el Estado Federal ha ganado cada vez más competencias. ${ }^{80}$ En tiempos de la euforia del "federalismo cooperativo" fue introducido en 1969 el nuevo inciso sobre los "deberes comunitarios" (Art. 91 a y b GG) ${ }^{81}$, que por supuesto son especialmente cuestionados en la actualidad.

Si nos preguntamos por las fuerzas reales e ideales que se hallan detrás de las diferentes modificaciones (federales) de la Constitución, nos encontramos con gran parte de las potencias que dieron forma a la Constitución y que también se encuentran presentes en las otras modalidades de cambio: partidos políticos (en jornadas partidarias y debates parlamentarios), praxis constitucional, profesores de derecho público y expertos en

80 Por ejemplo, la responsabilidad legislativa en el caso del aseguramiento económico de los hospitales (Art. 74 Inc. 19 GG), ya desde 1959 la responsabilidad por la producción y el uso pacífico de la energía nuclear (Inc. 11a Ibíd.) por la recolección de los residuos, por el cuidado de la calidad del aire y la reducción del ruido (Art. 74 Inc. 24 GG) en el año 1972 y la responsabilidad por la educación superior (Art. 75 № 1a GG) en el año 1969.

81 Con relación a esto ver I. von Münch/J. A. Frowein, VVDStRL 31 (1973), p. 13 ss., 51 ss.; S. Marnitz, Die Gemeinschaftsaufgaben des Art. 91a GG als Versuch einer verfassungsrechtlichen Institutionalisierung der bundesstaatlichen Kooperation, 1974. 
informes y trabajos (en concreto el informe Troeger de 1966), las reuniones de profesores de derecho público (en concreto 1960 y 1962, VVDStRL 19, p. 1 ss. y también 21, p. 66 ss., y 1972, VVDStRL 31, p. 13 ss.), tribunales, etc. Todos ellos participan de la transformación, son parte de estos procedimientos de adaptación y de resistencia, de producción y recepción. Por cierto: las tareas y especialidades, formas y procedimientos pueden ser mencionados - pero el último "movens" de la historia de la Constitución no se puede captar de esta manera. Para el futuro solamente es posible decir de manera muy general que la Ley Fundamental tendrá que hacer frente a nuevas necesidades pero también a una nueva abundancia ${ }^{82}$; a la escasez de recursos (por ejemplo energéticos y medioambientales) y a la búsqueda de caminos que posibiliten involucrar a la juventud en el Estado Constitucional a través de un Estado Cultural, para lo cual deben analizarse las transformaciones tecnológicas y las nuevas posibilidades brindadas por los medios.

Si y cómo puede darse esto a través de la interpretación constitucional, la "transformación constitucional" o la modificación constitucional, no lo podrá predecir nadie. Podría tratarse de procesos que no se vean impulsados solamente por causas económicas o políticas, que abarquen de manera amplia el desarrollo cultural.

El tiempo se hace presente justamente en estos procesos, judicialmente se vuelve tangible mucho después (de la interpretación constitucional transformada a la modificación constitucional formalizada). Desde lo socio-cultural es perceptible aún más tempranamente por sismógrafos como el arte y la literatura. La percepción jurídica de la transformación se $\mathrm{da}$, en general, en la fase final. Desde el punto de vista de la teoría constitucional se debe prestar atención ahora a los procesos culturales, a sus manifestaciones y a sus poderes de formación.

82 Para información general al respecto ver H. F. Zacher, VVDStRL 38 (1980), p. 153 (155). 


\section{Tematización del tiempo desde un enfoque científico cultural}

\subsection{La construcción de un puente hacia una compleja conceptualización cultural del tiempo - el tiempo como categoría cultural}

\subsubsection{Las Constituciones como garantes de continuidad y cambio}

La evaluación de la situación ha demostrado cómo las Constituciones de los estados constitucionales se desarrollan entre la tradición y el futuro e intentan demostrar su importancia; es en su conjunto una impactante historia del desarrollo ${ }^{83}$ en la que, sin embargo, algunos aspectos de la "herencia" cultural han sido descartados u olvidados. ¡La "Constitución en el tiempo", apreciada en el contexto más amplio del desarrollo del estado constitucional, no es un tiempo sin Constitución! Desde entonces no existe la posibilidad de reflexionar sobre el tiempo al margen de los elementos constitucionales - ni siquiera en vísperas de cambios constitucionales ${ }^{84}$. El factor tiempo influye especialmente en los cambios constitucionales, ya que se trata de la creación de una Constitución "nueva". El tiempo nuevo comienza generalmente con la creación de una Constitución. En la medida en que se acercan la interpretación y la creación de una Constitución en el marco de los tipos constitucionales

83 El refinamiento de los instrumentos y procedimientos alcanzado en Alemania (por ej. el voto en disidencia constitucional y el Art. 79 inc. $3 \mathrm{GG}$ ) hasta permiten hablar de un "progreso" en el perfeccionamiento del estado constitucional. Por supuesto que los instrumentos del estado constitucional que permiten la inclusión de desarrollos novedosos no son per se instrumentos para el "progreso". Las reformas no conducen necesariamente a un mejoramiento.

84 Ex post puede observarse que los desarrollos históricos tienen lugar de manera más bien continuada. Para el jurista constitucional, que acorde a la particularidad del derecho debe aferrarse a lo externo, tangible, como por ej. los plazos, resultan menos continuados: una reforma constitucional culmina a través de un particular procedimiento preestablecido en un "momento temporal" determinado; un voto en disidencia se objetiva -quizás tras un larga discusión previa en la ciencia y en la corte- de una vez. Se decide entonces una sola vez la reforma total de una Constitución como la suiza (o se la descarta). 
occidentales $^{85}$, se relativiza la significación de la creación de la Constitución y con ello el así llamado "nuevo comienzo". Justamente el enfoque constitucional cultural construye puentes entre la vieja Constitución y la nueva, que la observación jurídica formal, tergiversada por el dogma de la soberanía del pueblo, no puede visualizar al fijarse exclusivamente en el acto pensado como un estallido creativo de una Constitución. Un ejemplo: Muchos aspectos de la Constitución de Weimar ya no estaban vigentes antes de que los actos revolucionarios del régimen nacionalsocialista las derogaran formalmente. A la inversa, algunos principios constitucionales aún vigentes formalmente han cambiado con mayor profundidad a lo largo del tiempo, de lo que puede reconocerlo la simple apreciación jurídica formal: ya sea a través de profundas reformas constitucionales formales que desencadenan amplias repercusiones, o a través de la "transformación silenciosa" de la interpretación del mismo texto. Las profundas modificaciones de la Constitución de los EEUU a lo largo de 200 años de historia solamente pueden ser apreciadas desde un enfoque científico cultural.

En la actualidad, nuestra reflexión sobre el "tiempo" siempre tiene lugar en el contexto de Constituciones concretas que sirven de ejemplo para el establecimiento de una tipología: las Constituciones como reglamentaciones liberales del pluralismo intentan ser justas con el tiempo en un sentido doble: a través de la proposición de procedimientos que apacigüen y eviten los conflictos que traen consigo los cambios sociales, pero también a través de la creación de institutos que garanticen la estabilidad y aseguren la identidad del bien común individual y del comunitario político en los procesos de cambio ${ }^{86}$. Las Constituciones

85 Véase P. Häberle, Verfassungsinterpretation und Verfassungsgebung (1978), en: íbid., Verfassung als öffentlicher Prozess, 1978, p. 182 ss.; véase también mi comentario en: AöR 106 (1981), p. 149 ss.

86 Probablemente exista una relación óptima entre las partes "receptivas" más bien orientadas al pasado y las partes "prospectivas" orientadas al futuro de las Constituciones de los estados constitucionales. Un exceso de "nuevos comienzos" podría tornar demasiado lábil la nueva reglamentación, un exceso de acciones receptivas de las fuerzas constitucionalistas 
crean y conservan una parte de la continuidad cultural ${ }^{87}$. ¡Cuán profundamente se encuentra moldeada hace dos siglos, por ejemplo, nuestra conciencia acerca de la dignidad humana, la libertad (cultural), la tolerancia, la división de poderes, el pluralismo, etc.! Sin embargo, nuestra conciencia jurídica moderna al mismo tiempo también está impregnada de la idea de que el derecho y la justicia pueden ser transformados, que la "reforma judicial" es indispensable para el derecho, y hasta llegar a la consecuencia de una "reforma de las reformas".

\subsubsection{El tiempo como categoría cultural e interdisciplinaria}

La categoría "tiempo", tal como se la concibe en el derecho constitucional, se refiere en primer lugar a la estructuración temporal de los actos cotidianos del ser humano (y de sus "puntos de vista" con componentes objetivos y subjetivos ${ }^{88}$ ) y de su

(¿cómo en el GG?) podría exigir demasiado pronto reformas constitucionales u otros tipos de transformaciones. Un enfoque que, de ser posible, propone contemplar el desarrollo de las Constituciones en el tiempo, evitaría ambos extremos. Desde la perspectiva temporal podría recomendarse, establecer una equilibrada "mezcla" entre simples normas de competencia por un lado y "urgentes" mandatos constitucionales por el otro. Si se postulan demasiados -irrealizables- mandatos constitucionales, la Constitución pierde credibilidad, porque no podrá cumplir con todos simultáneamente. Si se reconocen solamente las competencias formales, el carácter de exigencia de las Constituciones se torna demasiado débil y difuso. Habría que construir una escala de técnicas de cómo el legislador constitucionalista incorpora el tiempo en la Constitución. Junto a la mencionada "gran" escala desde la modificación de la Constitución, pasando por el voto en disidencia hasta la transformación a partir de la interpretación, aparecería "en pequeña escala" otra diferenciación más: de la declaración programática y de la simple competencia formal (Art. $15 \mathrm{GG}$ ) a través de la competencia material (Art. 74 No. 16 GG) al mandato constitucional, por ej. en el Art. 6 inc. 5 GG.

87 Un aspecto parcial puede encontrarse, por ej., en la discusión acerca de la continuidad entre los historiadores: véase H. M. Baumgartner, Kontinuität als Paradigma historischer Konstruktion, en: Philosophisches Jahrbuch 1973, p. 254 ss.; fundamentalmente ahora: R. Kosseleck, Vergangene Zukunft. Zur Semantik geschichtlicher Zeiten, 1979.

88 El tiempo posee también en el plano constitucional componentes objetivos y subjetivos. Por un lado se encuentran plazos establecidos por la objetividad del tiempo (como en el Art. 68 inc. 2 GG), por el otro, regulaciones del tiempo que contienen elementos subjetivantes, o sea que reparan en las impresiones de los individuos. Un ejemplo para los componentes subjetivos es la expresión "de inmediato" -de frecuente aparición- (por ej. en el Art. 63 inc. 4 frase 1, Art. 76 inc. 2 frase 3, Art. 115b* inc. 2 frase 2, Art. 115 I 


\section{comunidad. Esta conciencia y comprensión del tiempo ${ }^{89}$ como marca estructural de las reglamentaciones sociales y experien- cias humanas no se encuentra junto a, sino en relación con la conceptualización del tiempo en las demás ciencias ${ }^{90}$ y artes, porque todas ${ }^{91}$ ellas son en última instancia expresiones de una}

inc. 2 frase 3 GG, Art. 101 inc. 2 frase 2 de la Constitución de Hessen, Art. 21 inc. 2 frase 1 Constitución de Niedersachsen, Art. 52 inc. 3 frase 2 Constitución de Nordrhein-Westfalen). Claramente también se da lugar a percepciones subjetivas del tiempo si algo es "calificado de particularmente urgente" (Art. 76 inc. 2 frase 3 GG) 0 es "considerado urgente", mejor dicho "calificado" como tal (Art. 84 inc. 5 frase 2, Art 85 inc. 3 frase 3, Art 115d inc. 2 frase 1 GG), o cuando la situación "exige una actuación inmediata" (Art. 115a inc. 2 frase 1, Art 115i inc. $1 \mathrm{GG}$ ) 0 algo ya no puede ser realizado "a tiempo" (Art. 115 inc. 2, inc. 3, frase 2, Art. 115 e inc. $1 \mathrm{GG}$ ). Formulaciones de este tipo son especialmente abundantes en las disposiciones del GG para el caso de defensa (Art. 115a ss.). El estado de excepción justifica la percepción más subjetiva del tiempo en aquellos procedimientos que en otra situación se encontrarían temporalmente prefijados, lo cual le permite ganar en flexibilidad y capacidad de reacción. También cuando el derecho constitucional se refleja en el derecho ordinario se debe, llegado el caso, reparar los momentos subjetivantes del tiempo, como por ejemplo en el retorno a la situación anterior. Sin embargo, ante una recepción tardía a causa de una inusual duración del envío postal, el plazo se encuentra -objetivamente- vencido. Pero ante la pregunta acerca de la reconsideración se hace uso de la percepción subjetiva del tiempo. Si el envío había sido realizado con suficiente antelación como para que, en condiciones normales de entrega, el mismo llegara a tiempo, no existirá razón para negar una reconsideración (BVerfGE 44, 302, 306; 50, 1, 3; Jurisprudencia constante)

*N.d.T.: aquí probablemente se trate del Art 115d.

89 Además del tiempo también es el "espacio" el que estructura la acción humana. Y quizás la teoría constitucional del tiempo y la del espacio, en última instancia, forman parte de lo mismo. Reflexiones acerca de una teoría constitucional del espacio en P. Häberle, Kulturpolitik in der Stadt - ein Verfassungsauftrag, 1979, p. 38 ss.; véase también R. Wendorf, Zeit und Kultur, 1980, p. 660 ss.

90 De la etnología: U. R. von Ehrenfels, Zeitbegriff und Stufenfolge in völkerkundlicher Sicht, Studium generale 19 (1966), p. 736 ss.; J. T. Fraser, The interdisciplinary study of time, Studium generale 19 (1966), p. 705 ss.; Idem (ed.), The study of time, 1972; R. W. Meyer (ed.), Das Zeitproblem im 20. Jahrhundert, 1964; W. E. Moore, Man time and society, 1963; J. Piaget, Die Bildung des Zeitbegriffs beim Kinde (1955), 1974; M. Schöps, Zeit und Gesellschaft, 1980; H. Yaker (ed.), The future of time, men's temporal environement, 1971; J. A. Roth, Time tables, 1963.

91 La capacidad de creación de las ciencias humanas no debería subestimarse. Éstas también influyen en la decisión de qué textos clásicos son transmitidos como tales, definen la "herencia cultural", la cual no puede prescindir por ej. de Montesquieu. Las ciencias jurídicas trabajan aquí mano a mano con las ciencias políticas y las ciencias históricas. El redescubrimiento de Tocqueville también fue beneficioso para la comprensión del estado constitucional como un logro europeo en común. 
época cultural. Con la misma certeza con la que se puede afirmar la "autonomía" del derecho (y de las ciencias jurídicas) ante lo social (y las ciencias sociales) ${ }^{92}$, es posible demostrar que el derecho, en especial el derecho constitucional, forma parte de la cultura general de una época, o sea también también de la reflexión sobre una época y el actuar en y a través de una época (y también de su "tempo") ${ }^{93}$.

La conceptualización interdisciplinaria del tiempo que atraviesa las ciencias y las artes de una época ciertamente es compleja ${ }^{94}$ y encuentra sus límites en la relatividad de las

92 Cf. K. Larenz, en: FS E. R. Huber, 1973, p. 291 ss.

93 La vocación del jurista por una tarea específica, la separación de "la justicia de la injusticia" y "el orden del caos", y una fuerte confrontación entre el proceso abierto de la vida política, social y cultural y un ámbito regulado jurídicamente, es decir, también la política y el derecho (cf. W. Henke, en: Der Staat 19 [1980], p. 181, [190f. bergen]), un decisionismo encubierto. La renuncia a incluir desde un inicio, tanto en la interpretación de la Constitución como en el análisis teórico de las Constituciones, la vida constitucional como proceso real y propiamente cultural con sus variados impactos (efectivamente presentes) sobre el derecho constitucional, conduce a un sesgado racionalismo positivista en lo jurídico. Éste no puede explicar la variedad de disputas en torno a la interpretación del derecho constitucional presentes en la teoría y en la práctica, menos aún tomar decisiones en base a parámetros superadores, sino solamente seleccionar entre lo "correcto" o "incorrecto". Solamente la referencia a los reales trasfondos socioculturales de las divergencias en la interpretación, puede elaborar parámetros más racionales para los conflictos en torno a decisiones jurídicas y profundizar de esta manera la discusión legal, sin delegar esto a la esfera política. En la medida en que los procesos socioculturales subyacentes y preexistentes al proceso de elaboración de las normativas legales a través de la interpretación de las normas, se vuelven más abundantes en el contenido de normativas jurídicas abiertas, posibilitan una interpretación constitucional profundizada gracias al enfoque científico cultural. Por supuesto deben considerarse el texto como límite de la interpretación y la disciplina metódica, pero tanto el texto como la disciplina muchas veces son sobrevalorados (lo cual no es de ninguna manera una contradicción); por supuesto es otra la opinión de B. Schlink, en: Der Staat 19 (1980), p. 73 (84), que entonces debe relativizarse por sí mismo (p. 91, cf. también 105): ninguna pretensión de claridad metodológica puede sobrepasar los límites de las ciencias jurídicas en tanto disciplina hermenéutica.

94 Cf. solamente N. Luhmann, en: W. Schluchter (Ed.), Verhalten, Handeln und System, 1980, p. 32 ss., aquí p. 56 ss.; ver tamb. idem, Soziologische Aufklärung 2, 1975, p. 103 ss.; cf. también la diferenciación de N. Elias entre dos conceptualizaciones del "tiempo": el tiempo físico ("flujo continuo de acontecimientos sucesivos") y el tiempo histórico y social de la utopía como „tiempo en proceso", en el que se une el pasado a través del presente con el futuro (FAZ del 26/6/1981, p. 25, Coloquio sobre la utopía en Bielefeld). 
particulares conceptualizaciones del tiempo y de los horizontes temporales, presentes en los diferentes campos y especialidades científicas. Asimismo, gracias a la correspondencia existente entre la cultura en las diferentes épocas temporales y una determinada percepción del tiempo ${ }^{95}$, pueden identificarse aspectos de una concepción temporal cultural común y, más precisamente, condicionada culturalmente, que puede ser de ayuda para el derecho constitucional ${ }^{96}$. La conciencia de que las transformaciones tienen lugar cada vez con mayor velocidad, podría ser un aspecto común, que resulta válido tanto para las Constituciones y su cultura como para las demás ciencias sociales y las artes.

En sentido inverso, las ciencias sociales no deben interpre$\operatorname{tar}^{97}$ la conceptualización particular del tiempo en las ciencias jurídicas, por ej. en cuanto a los diferentes instrumentos del derecho constitucional, a partir de la exigencia de una "recepción inmediata y total del cambio en el derecho"98. Esto implicaría

\footnotetext{
95 En este sentido: R. Wendorff, Zeit und Kultur, 1980, por. ej. p. 653 ss.

96 La comprensión de la concepción del tiempo presente en una determinada cultura jurídica y expresada en la Constitución, también se alcanza a partir del estudio de la autocomprensión del ser humano y especialmente del ciudadano.

97 Esto no significa que haya que plantear estrategias de inmunización. Por ej, la diferenciación entre „el tiempo en el derecho constitucional" y "la Constitución en el tiempo" puede relacionarse sin dificultades con la diferenciación que propone N. Luhmann entre un presente puntual (irreversible) y un presente continuo (reversible), si se puede establecer un análisis paralelo (en un plano más general) de la continuidad y el cambio en las Constituciones, o mejor dicho, de sus contenidos culturales y su vinculación con un tiempo determinado, véase íd., en: W. Schluchter (Ed.), (ebd.), p. 41 ss. y 47 ss. La necesidad de contemplar en estudios interdisciplinarios los diversas contextos de acción y ámbitos de concreción de las distintas ciencias (especialmente aquellas orientadas a la práctica), se constituye muchas veces en una barrera práctica para la comunicación.
}

98 El derecho (constitucional) y su ciencia no se harían un favor si cedieran rápidamente ante cada cambio social, si reaccionaran ante cada desafío o hasta provocación cultural. Perderían su importancia en el accionar conjunto con los demás factores y procesos culturales. El camino entre la afirmación y el cambio seguramente es difícil, pero es el camino del derecho (constitucional). También la independencia judicial pertenece a los instrumentos del estado constitucional que quieren y pueden estar al servicio del "valor intrínseco" del derecho frente a otros procedimientos. Lo que finalmente orienta el curso de la historia 
la disolución del derecho, pérdida de la seguridad jurídica y con ello la de un elemento de justicia así como la negación de la Constitución, que según su "telos" debe ser un "ley fundamental": para ello es preciso un mínimo de permanencia y estabilidad (por ej., a través de la recepción, del disciplinamiento de la creación jurídica judicial, de procedimientos cuidadosos en las reformas ${ }^{99}$, etc.), sin ignorar la importancia de una comprensión dinámica y "procedimental" de la Constitución ${ }^{100}$. Aquí coincidimos con $R$. Wendorff, quien intenta aportar una "compensación, un contrapeso a las unilateralidades de nuestra concepción temporal lineal" 101 , busca "valores permanentes"102 y espera de esta manera una "polaridad" repleta de tensiones en el mundo occidental ${ }^{103}$.

(constitucional), es un interrogante al, o más bien a los, "sujetos" de la historia. Sólo puede ser respondido a partir de creencias, un ejemplo para ello es la expresión "el sentido posible de la historia para el hombre" en el sentido que le otorga Sir Popper.

99 En las reformas legales se demuestra, cuán necesarios son los procesos de desarrollo cultural para que el -nuevo- derecho pueda echar "raíces". Un eventual exceso de reformas en el ámbito jurídico ya no es suficiente. Por más reformas "desde arriba" que realice el legislador: si no se les concede suficiente tiempo a las reformas para que puedan operar en la práctica, se tornan inútiles. El proceso de la vigencia jurídica no se logra a partir de la proclamación de una norma en el Boletín Oficial del estado, porque el establecimiento de la confianza en la norma que deben tener sus destinatarios, precisa de tiempo. Las condiciones para la validez de las normas jurídicas son, en definitiva, de naturaleza cultural: no son solamente "estatales" ni solamente "sociales", ni se fundamentan sólo en lo objetivo ni tampoco únicamente en lo subjetivo.

100 Las distintas "escuelas" podrían diferenciarse justamente a partir de una comprensión diferente del tiempo, por sus "posicionamientos" diversos ante el tiempo: la más antigua piensa de manera más bien estática, la línea iniciada por R. Smend es más bien dinámica. Según el caso, es distinta la relevancia de la normatividad en tanto "inviolabilidad"; cf. también W. R. Schenke, en: AöR 103 (1978), p. 566 (570 ss.).

101 R. Wendorff, Zeit und Kultur, 1980, p. 655.

102 R. Wendorff, ebd., p. 657.

103 Véase R. Wendorff, ebd., p. 653 ss.: „Polarität, Spannung, Ausgewogenheit”. Los planos temporales se entrecruzan de varias maneras: el historiador constitucionalista, que relata lo "pasado", al mismo tiempo se desempeña más o menos concientemente como comentarista del presente; el dogmático constitucionalista también extrae sus concepciones previas y toma préstamos de la historia, así como también sus esperanzas hacia el futuro; el político constitucionalista del "principio esperanza" también vive del pasado y del presente, y sea solamente porque desarrolla un programa de contrastación (una "utopía concreta") con relación a los mismos. 
Detengámonos aquí: un "concepto puente" para esta incorporación del derecho constitucional y sus problemas del tiempo es la "cultura", por lo cual el método para el "establecimiento de este puente" debe estar orientado por la ciencia de la cultura: solamente así aparecen la vinculación teórica del estado constitucional y el tiempo y se posibilita una interpretación simultánea desde el pasado y la apertura, así como su fundamentación como parte de un "proceso cultural de crecimiento" (L. Kolakowski). La "cultura" es la "sustancia" a partir de la cual surgen, se transforman y "envejecen" ${ }^{104}$ las Constituciones.

\subsection{La interpretación constitucional a partir de las ciencias culturales}

\subsubsection{El enfoque desde las ciencias culturales}

El punto de partida es el reconocimiento de que la Constitución no es solamente una reglamentación legal para juristas que debe ser interpretada por éstos según viejas y nuevas reglas del arte, sino que también actúa principalmente como guía para quienes no son juristas: los ciudadanos. La Constitución no es solamente un texto jurídico o un "reglamento normativo", sino también la expresión de un estadío del desarrollo cultural, un medio para la autorepresentación cultural del pueblo, reflejo de su herencia cultural y fundamento de sus esperanzas. Las Constituciones vivas no son solamente obra de los juristas y políticos, sino la obra de todos los intérpretes de la Constitución en la sociedad abierta. La Constitución es, en forma y contenido, más bien expresión y transmisión de la cultura, un marco para la (re)producción y recepción cultural y almacenamiento de "informaciones", experiencias ${ }^{105}$,

\footnotetext{
104 De alguna manera se ejerce el poder estatal desde el pueblo hacia la cultura y viceversa, al menos en una concepción amplia de la cultura y un concepto abierto de la cultura. 105 El derecho (constitucional) también posee otra relación particular con el tiempo. En sus "institutos" almacena experiencias culturales. Sí, son una porción de cultura. Las experiencias surgidas de cientos de años de cultura jurídica romana, por ej., hacen su aparición aún hoy en día en el derecho civil. La teoría de Montesquieu acerca de la división de poderes
} 


\section{vivencias, sabiduría ${ }^{106}$ cultural tradicional. Su validez cultural es consecuentemente más profunda ${ }^{107}$. Esto fue captado muy bien por $H$. Heller en la recreación de la imagen de Goethe, la Consti- tución es "una forma acuñada que se va desarrollando en la vida".}

como experiencia en cuanto a la inclinación del ser humano hacia el abuso de poder, es un ejemplo para muchos. Justamente el enfoque científico de la experiencia incorpora el tiempo -y toda una cultura- a su manera en la teoría constitucional. ¡La Constitución es en muchos aspectos una reacción ante las experiencias de Weimar! El mínimo de educación que necesitan y deben transmitir especialmente las constituciones liberales, también surge de la continuidad y estabilidad en el tiempo. ¡Las metas educativas normatizadas son, al igual que muchas reglas jurídicas, una porción de experiencia cristalizada!

106 En el sentido antropológico cultural o, mejor dicho, etnológico y no jurídico, B. Malinowski no utiliza por casualidad el concepto de "constitución" en: Eine wissenschaftliche Theorie der Kultur (1941), 1975, p. 142. La teoría del derecho constitucional en el sentido que aquí le otorgamos, no puede obviar el reconocimiento de la dimensión cultural más profunda de las Constituciones de los estados constitucionales.

107 La teoría del derecho político hasta el momento ha aportado poco al enfoque científico cultural en la interpretación constitucional, mejor dicho la delimitación de la "cultura constitucional". Los trabajos científicos culturales de H. Heller (Staatslehre, 1943, en especial p. 32 ss.) pertenecen aquí por supuesto, así como también los trabajos en humanidades y de historia de la cultura de R. Smend, E. Kaufmann y G. Holstein (Referencias en: P. Häberle, Kulturstaatlichkeit und Kulturverfassungsrecht, en elab.); pero no han sido profundizados a partir del estudio de la Constitución; extrañamente no condujeron a una "cultura constitucional" ni la discusión en torno a "estado y sociedad" o "Constitución y realidad constitucional" ni la controversia de los "métodos de la interpretación constitucional", ni la discusión más profunda de los años 60 acerca del Derecho público eclesiástico y tampoco el actual "debate de los valores fundamentales". Ya sólo la comparación constitucional hubiera aportado algo al enfoque científico cultural. El derecho privado no ha olvidado el trabajo con los puntos de vista de la "cultura del derecho" (F. Wieacker, Privatrechtsgeschichte der Neuzeit, $2^{a}$ edición, 1967, p. 13, 26; J. Esser, Grundsatz und Norm in der richterlichen Fortbildung des Privatrechts, $3^{a}$ edición, 1974, señala los fundamentos culturales del derecho -comunes a las naciones culturales- y a principios jurídicos reconocidos por todas las naciones culturales, por ej. p. 28, 34 ss.; 378); distinto es en el derecho Constitucional: aquí la idea de una cultura jurídica prácticamente no se ha difundido aún. Esta omisión seguramente tenga causas políticas e histórico-científicas muy alemanas. Por un lado, era tan fuerte la fascinación por el aspecto político de la Constitución, que el aspecto cultural pasó inadvertido; por otro lado se concibió a la cultura -siguiendo una tradición alemana- como tan apolítica y "no jurídica" que difícilmente pudiera convertirse en objeto de la teoría del estado y de la Constitución (véase por ej. Ios dispersos comentarios al margen acerca de la dependencia cultural de la solidaridad en G. Jellinek, Allgemeine Staatslehre, $5^{a}$ reimpresión de la $3^{a}$ edición (1928), 1966, p. 253). Finalmente podría considerarse como causa la fijación en la Constitución escrita. Con esto podría describirse la historia de las discusiones en la teoría del derecho político como proceso de la producción y recepción cultural. 
En especial los preámbulos y las metas educativas (expresas o implícitas) (como tolerancia, sentido de la responsabilidad, solidaridad), también los símbolos y los textos constitucionales entendidos en sentido amplio, como los textos de los clásicos ${ }^{108}$, expresan los contenidos culturales de las Constituciones a partir de medios más bien no jurídicos y en un lenguaje no jurídico, que resulta más comprensible para los ciudadanos, pero también más "idealista" que los demás textos constitucionales. Son una especie de "versión no jurídica" de la Constitución. Como artículo de fe pretenden expresar el "espíritu" del cual surge el lado jurídico constitucional de las Constituciones y que debe ser transmitido. Por ello la identidad de una Constitución, ubicada entre la transmisión, la herencia y la experiencia histórica por un lado y la esperanza, las posibilidades y la capacidad de moldear el futuro de un pueblo por el otro, solamente puede ser comprendida totalmente a partir de un enfoque científico cultural $^{109}$. Gracias a los métodos de trabajo interdisciplinarios (científico-culturales) se torna visible lo previo a la creación de la Constitución, lo que la sostiene y lo que la impulsa a continuar: los procesos creadores primarios del cambio (cultural) (así como también la continuidad cultural), que el estado constitucional va abordando "con el correr del tiempo" y que procesa (a posteriori) en el sentido de "challenge and response" o ensayo y error en el sentido de Popper. El estado constitucional recepciona las múltiples formas del cambio en las artes y ciencias, en la política ${ }^{110}$ y la economía, aunque también se impone a partir

\footnotetext{
108 Una relación entre la medición musical del tiempo, el sentido del ritmo, el tiempo de reinado y el honor del reinante se realiza de manera insuperable en Shakespeare (cf. Ricardo II, acto V, escena IV). Una cita acerca del tiempo también en: "A vuestro gusto" (acto II, escena VII, Jacques).

109 Con relación al enfoque científico cultural véase P. Häberle, Kulturpolitik in der Stadt - ein Verfassungsauftrag, 1979, p. 43 ss.; íd. Kulturverfassungsrecht im Bundesstaat, 1980, p. 62 ss., y también en: VVDStRL 38 (1980), p. 114 ss. (Diskussion); ibíd., en: FS H. Huber, 1981, p. 211 (212, 228 ss.).

110 Tan difícil como lo es capturar lo político del derecho constitucional en precisas transcripciones como "otro estado de agregación", etc., tan difícil es identificar lo cultural "del", "en" y "tras" el derecho constitucional. ¿Cuál es "el motor" de la vida constitucional, de
} 
de la producción propia (especialmente a través de ésta ${ }^{111}$ ). La interpretación de la Constitución desde el enfoque científico cultural busca una ampliación de los horizontes científicos y una profundización, mejor dicho clarificación, del trasfondo del estado constitucional ${ }^{112}$; de esta manera posibilita una tematización más "profunda" del "tiempo en la Constitución" y de "la Constitución en el tiempo", al inscribir la Constitución en el contexto cultural de su época. El tiempo se refleja en desarrollos culturales y cristalizaciones "más tempranamente" y con "mayor precisión" que en las formas y los procedimientos jurídicos, contenidos e institutos; la "reflexión acerca de las posibilidades"113 corresponde primariamente a las artes y a la filosofía ${ }^{114}$.

las normas constitucionales? Es lo cultural y no solamente lo político. Los principios constitucionales surgen de procesos culturales, se transforman a partir de estos. La primaria, a veces exclusiva, fijación en lo político, ha ocultado al contexto más amplio de lo cultural. Esta preponderancia de lo cultural también puede basarse en las teorías básicas de las ciencias sociales: véase por ej. la comprensión de sí mismo de T. Parsons como "determinista cultural" en: íd. Gesellschaften, 1975, p. 173 ss. (175); críticas en W. Schluchter, en: W. Schluchter (ed.), Verhalten, Handeln und System, 1980, p. 106 (115 ss.), quien sin embargo se remite, al abordar la cultura y su vinculación con todos los ámbitos de la vida (también el jurídico político), al concepto sociológico de la "interpenetración", es decir un cambiante entrelazamiento y una influencia mutua (p. 130 ss.). El cambio cultural, en general precede a las formas jurídicas de procesamiento del mismo. Esto se puede mostrar tanto a partir de ejemplos de modificaciones constitucionales (¡las tareas comunitarias del Art. 91 a y b GG!) como en las reformas del derecho básico. La descriminalización del tradicional derecho penal sexual en los años 70 respondió a cambios culturales más profundos en el ámbito ético y social.

111 Por eso es cuestión de refinar, mejor dicho sensibilizar, aquellos métodos e instrumentos de los estados constitucionales que recepcionan los procesos de desarrollo que dan forma a la dimensión macro de "la Constitución en el tiempo" y la dimensión micro del "tiempo en la Constitución".

112 La comprensión de la Constitución desde un enfoque científico cultural no implica la renuncia a los diferentes juegos de los probados modos jurídicos de interpretación constitucional y de sus funciones; estos mantienen su derecho relativo: como interpretación constitucional "material" o sociológica, "positiva" o "histórica".

113 Cf. P. Häberle, Demokratische Verfassungstheorie im Lichte des Möglichkeitsdenkens (1977), en: íd., Verfassung als öffentlicher Prozess, 1978, p. 1 ss.

114 El jurista, por el contrario, trabaja más bien a posteriori y de manera relativamente "superficial" y principalmente técnica sobre lo más visible; trabaja con el tiempo (es decir, con la tradición y el cambio, la herencia y la esperanza, la historia y la apertura al futuro) más bien de "segunda mano". 
Los impulsos culturales más profundos y las corrientes más "finas", que conducen a la "transformación de la Constitución", a los efectos anticipados de las leyes (o no), se vuelven accesibles a mediano plazo a través de una interpretación constitucional "exclusivamente jurídica". Temporalmente por lo general solo se pueden registrar resultados. Estas configuraciones legales se atienen, con buenas razones, por más tiempo a las tradiciones que en el caso de los "reflejos culturales" de otras ciencias pero también de las artes ("sismográficas") y que en el espectro de otros "medios" (como la política). Las amplias posibilidades de una historia pensada de manera abierta solo pueden ser apreciados parcialmente por el jurista con su "oficio" y su "arte"; pero éste debe saber que se encuentra posicionado en un contexto cultural más abarcativo.

Todo esto es el correlato (no sucedáneo) de la Constitución como conjunto jurídico de técnicas formales y formalizadas, métodos jurídicos, dogmas, institutos y principios de contenido. La elaboración de la dimensión cultural de la Constitución no pretende poner en cuestión un "arte jurídico seguro". El jurista constitucional hasta debe persistir en los instrumentos y contenidos más externos - por el reconocimiento de la Constitución como una estructura legal específica, lo cual ésta también es. Pero la Constitución es más que esto: para el ciudadano y la comunidad es una porción de fundamento cultural y de identidad ${ }^{115}$.

La sociedad abierta encuentra de esta manera su fundamentación cultural. Ésta ocurre de manera muy indirecta y superficial, fragmentada y limitada por el derecho como tal.

\footnotetext{
115 El enfoque científico cultural sólo pretende complementar la interpretación constitucional tradicional con lo que vivencian, practican y comprenden los intérpretes constitucionales en sentido amplio, los ciudadanos "no jurídicos". Ambas partes en conjunto, la jurídica y la científico cultural, hacen al todo en la Constitución. Esto tiene consecuencias, por ej. en lo educativo: la misión pedagógica del GG no exige tanto la transmisión del conocimiento teórico-jurídico - esto es tarea de los juristas corporativos. Se trata de la transmisión de la Constitución como marco para la cultura y como enunciado parcial sobre la cultura, o mejor dicho, las metas educativas. En este sentido la Constitución es tanto un libro de estudio para los alumnos como para los profesores.
} 
Otras sustancias se tornan fundamentales: la unión cultural de un pueblo, sus metas educativas llevadas a la práctica, etc., en resumen: la cultura de un pueblo. También la "cultura constitucional" que subyace a las normas constitucionales y las rodea es parte de esto.

El ampliamente discutido consenso básico social sólo es un aspecto parcial: la sociedad abierta es constituida sobre todo a partir de un consenso cultural. No está "escrito" en la Constitución; allí sólo se lo encuentra en parte, pero es en definitiva el "lazo espiritual" que unifica a un pueblo hoy y en las sucesivas generaciones: por ej. en forma de textos clásicos, jornadas conmemorativas nacionales y otras "cristalizaciones culturales" existentes en el derecho constitucional. Dicho de otra manera: La Constitución pluralista es desde un principio una referencia al contexto cultural de un pueblo, como éste se ha concebido a lo largo de largos períodos culturales. Cómo lo logra -especialmente en la línea del tiempo- será analizado en detalle a continuación: a partir de las palabras claves de cultura constitucional, interpretación específicamente cultural de la Constitución y libertad cultural.

\subsection{2. "Cultura constitucional"}

El concepto de "cultura constitucional" es el que mejor se presta para expresar lingüísticamente el entrelazamiento que se da entre el enfoque científico cultural y la interpretación de la Constitución ${ }^{116}$. Este concepto tiene por destinatarios activos y

\footnotetext{
116 El concepto de "cultura política" es discutido hace mucho tiempo; de la gran cantidad de literatura sobre la "cultura política" véase por ej.: P. Reichel, en: PVS 21 (1980), p. 382 ss. y la discusión por él impulsada: D. Berg-Schlosser, H. Gerstenberger, K. L. Schell/J. Schissler así como también 0. W. Gabriel, en: PVS 22 (1981), p. 110 ss., 117 ss., 195 ss. y también 204 ss.; G. A. Almond/S. Verba (ed.), The civil culture revised, 1980; H. Rausch, Die politische Kultur in der Bundesrepublik Deutschland, 1980; M. y S. Greiffenhagen, Ein schwieriges Vaterland. Zur politischen Kultur Deutschlands, 1979, en especial p. 18 ss.; T. Stammen, en: J. Becker (ed.), Dreissig Jahre Bundesrepublik - Tradition und Wandel, 1979, p. 11 ss; véase también SPD-Grundwertekommission (ed.), Theorie und Grundwerte. Zur politischen Kultur in der Demokratie, 1980; además T. Rasehorn, en: Frankfurter Hefte, 1980, Cuaderno 9,
} 
pasivos, en primer lugar, al ciudadano y los grupos pluralistas, y no al jurista (constitucional). La cultura constitucional es la encarnación de los posicionamientos (subjetivos), de las valoraciones y del pensar, así como también de la acción (objetiva) del ciudadano y de los grupos pluralistas, de los órganos del estado, etc. con relación a la Constitución. ¡Su representación de la Constitución desde el rol de escritor, artista, trabajador, profesor, funcionario público es una porción de cultura constitucional! ¡La cultura constitucional es la versión no jurídica de la Constitución de una comunidad política!

Por ejemplo, los límites de la reforma constitucional no deben buscarse tanto en una jurídicamente denominada "cláusula de eternidad" como en el Art. 79 inc. 3 GG -una típica "norma de jurista"- como en las prácticas referidas a metas educativas orientadas a la dignidad humana y la tolerancia, la libertad y la igualdad: la "interpretación pedagógica de la Constitución" como vehículo de la cultura constitucional y el abordaje de la Constitución entendida de manera cualitativa, se tornan verdaderas garantías constitucionales ${ }^{117}$.

p. 18 ss.; w. Nw. En J. Schissler, en: ZfP 25 (1978), p. 154 ss. (Pie de pág. 1 ss.) y P. Häberle, Kommentierte Verfassungsrechtsprechung, 1979, p. 448 (Pie de pág. 69). Con relación a esto la "cultura constitucional" aún no posee una tradición. El objeto al que se refiere por cierto ya se ha abordado bajo otras denominaciones. La referencia al derecho constitucional como "derecho político" (R. Smend, también H. Triepel), el "ambiance" en D. Schindler, pero también las reflexiones más recientes sobre el contexto -cultural- de normas constitucionales brindan primeros puntos de vista para la elaboración de la "cultura constitucional". Se hace referencia a lo que se encuentra más allá del texto constitucional, a lo que lo rodea y a lo que lo supera, se trata del conjunto de valoraciones, orientaciones del pensar, costumbres y posicionamientos en los que el texto constitucional se haya inmerso y del cual surge, a partir del cual se modifica y ocasionalmente también se desvanece.

117 Un aspecto de la culura constiucional es la "cultura del derecho fundamental". El autor ha sugerido este concepto por primera vez en 1978 (P. Häberle, Verfassung als öffentlicher Prozess, 1978, p. 587 ss.) y lo ha precisado más tarde (en íd., Kommentierte Verfassungsrechtsprechung, 1979, p. 88 ss.). Nos referimos a la tesis de que la realidad del derecho fundamental no surge solamente de los textos jurídicos sobre los derechos fundamentales, sino de una amplia variedad de contenidos y funciones (culturales). El más refinado dogmatismo acerca del derecho fundamental (como en la República Federal de Alemania) no es garantía suficiente para que los derechos fundamentales realmente sean vividos. La "cultura de la libertad" se conforma a partir de un amplio conjunto de cuestiones: sentido ciudadano, 
Para que las Constituciones promulgadas se tornen cultura (constitucional), se precisa mucho tiempo. Por ello se debe relativizar la afirmación de que nuestro GG es la Constitución más liberal que se haya promulgado en suelo alemán a partir del interrogante acerca de cuán profundamente esta "cultura política" se encuentra arraigada en principios democráticos también en tiempos de crisis, hasta qué punto se identifica el ciudadano común de palabra y de hecho con los derechos fundamentales de los demás ciudadanos y no solamente con los propios ${ }^{118}, \mathrm{y}$ cuán respetuosamente es aceptada la Constitución por todos. La cultura constitucional es temporalmente más dependiente que las normas del derecho constitucional; pero a pesar de ello puede fundamentar más profundamente una Constitución.

La "cultura constitucional" debe ser diferenciada del derecho constitucional cultural. El "derecho constitucional

\begin{abstract}
el compromiso de los ciudadanos en cuanto a (sus) derechos fundamentales y su predisposición para asumir responsabilidades, tradiciones republicanas y virtudes (como existen especialmente en Francia, país que por ello no precisa de un perfeccionismo jurídico de los derechos fundamentales), ética del comportamiento de los medios, la toma de conciencia científica de los profesores de derecho público y su disposición a tomar en serio el postulado del pluralismo en todo sentido, otras éticas profesionales, "instancias" culturales como la literatura y los literatos, etc. Justamente la comparación cultural de los derechos fundamentales no puede ser realizada sin el concepto de "cultura del derecho fundamental", a causa de la declaración de sus diferencias y similitudes en los diversos estados constitucionales y la búsqueda de equivalencias funcionales para institutos jurídicos concretas.
\end{abstract}

118 La protesta popular en Baviera por violación de los derechos fundamentales (Art. 98 Const. Baviera) otorga una oportunidad única para alcanzar, con el tiempo, más cultura del derecho fundamental con los medios del derecho y en el Tribunal Constitucional. Quizás sea la "cultura constitucional" a la vez el tiempo "en el pensamiento" y la jactuación prática!, modificando un poco la expresión de Hegel. El develamiento del trasfondo cultural de las Constituciones de los estados constitucionales sirve tanto a la elaboración de un tipo ideal de "estado constitucional" a partir de elementos culturales, como también a la percepción de la cultura constitucional individual de cada pueblo. La "cultura del derecho fundamental" es muy diferente en Francia y en Alemania, por ejemplo en lo referente a la capacidad de imposición judicial aquí, y a la sensibilidad de la opinión pública como "guardianes de los derechos fundamentales" allá. Y por más influyentes que sean los contextos para los textos jurídicos, existe una genuina "herencia cultural" común a toda Europa en cuanto a los derechos fundamentales. En otras palabras: el enfoque científico cultural en el derecho constitucional no es una reducción al estado nacional, sino ambas cosas: individualización por un lado y generalización por el otro. 
cultural"119 hace referencia a los aspectos jurídicos culturales de la Constitución, con los cuales los demás aspectos como el del estado de derecho o el social se encuentran menos directamente vinculados. La "cultura constitucional" comprende, por el contrario, a todos, también a los ámbitos de creación de identidad preexistentes a la promulgación de la Constitución, presentes en la Constitución de una comunidad política del tipo del estado constitucional occidental ${ }^{120}$.

El derecho constitucional se diferencia, como todo derecho, de lo "simplemente cultural" a partir del compromiso con la ley. Lo cultural posee una validez propia y una vigencia propia, obra sin sanciones jurídicas directas ${ }^{121}$.

Para el ámbito democrático pueden mencionarse ámbitos en los que el derecho constitucional deja lugar a desarrollos propios de la cultura política ${ }^{122}$. La cultura constitucional incorpora

119 Los impulsos específicos para la cultura constitucional de un pueblo provienen de su derecho constitucional cultural. El vínculo entre la constitución de la cultura y la cultura constitucional no pertenece solamente al plano nominal. El arte y la ciencia ofrecen permanentemente "material", aportes creativos, que pueden compactarse en una porción de cultura constitucional. La preparación científica del parlamentarismo sirve tanto a la cultura constitucional, como el descubrimiento de las múltiples dimensiones de los derechos fundamentales favorece a la "cultural del derecho fundamental".

120 La opinión pública no sólo introduce lo político en la comunidad democrática; ella comprende, da vida e introduce también otro ámbito, no menos importante: el cultural. La opinión pública cultural no es solamente un factor en los procesos de desarrollo del derecho constitucional cultural. Ella actúa en todos los ámbitos de la cultura constitucional.

121 Esto se puede apreciar particularmente en la ética social. El derecho constitucional y familiar regulan sus asuntos solamente de manera fragmentaria. Qué cultura familiar (o de asociación) se desarrolla y cómo lo hace, se gesta según “leyes" propias. Toda igualación jurídica entre el hombre y la mujer no puede evitar que en lo sociocultural muchos ámbitos aún no se encuentren "igualados".

122 La "cultura política" muchas veces precede temporalmente a la cultura constitucional, también puede decirse que ésta constituye un específico estado de agregación de aquella. Sin embargo no existe una identificación completa. La cultura constitucional presupone un grado de mayor solidez, estabilidad, duración y objetivación que la "cultura política". No todo lo que es cultura política se constituye en cultura constitucional. La alusión a la "Constitución" en la expresión "cultura constitucional" debe ser tomada en serio: exige un mínimo de duración y capacidad de objetivación. El "estar a la altura" se ha tornado más sólido. La cultura constitucional es resultado del trabajo de muchas generaciones en torno a la Constitución. 
elementos de lo que en Alemania se denomina "cultura nacional": el comportamiento electoral de los ciudadanos, la predisposición a un "traspaso real del poder" (como en Inglaterra), tradiciones parlamentarias y código de honor practicado por los diputados, el rol del periodismo, también del ejercicio libre de la abogacía, sensibilidad, vigilancia y aceptación de la crítica de la opinión pública, todos estos son momentos de una "cultura constitucional" ${ }^{\prime 23}$.

La "cultura constitucional" podría convertirse de esta manera en un concepto clave que conjuga todos los aportes de los ciudadanos pensantes y actuantes, en especial de las ciencias, hacia una "Constitución en el tiempo". La expresión, "nosotros" debemos velar por la Constitución, debe ser extendida a todos los ciudadanos y en especial a todos los hombres de las ciencias. Por más difícil que sea "seguirle la pista" científicamente al tiempo, gracias al enfoque cultural constitucional se tornan más transparentes y tangibles las manifestaciones, los procesos de crecimiento, las transformaciones y los procesos de disolución.

\subsubsection{La interpretación especificamente cultural de la Constitución}

"Cuando dos leyes fundamentales expresan lo mismo, no es lo mismo". Esta afirmación de R. Smend de 1951 nos acerca a la cuestión de cómo es posible que los mismos textos jurídicos, por ejemplo los pactos de derechos humanos en oriente y occidente, pero también entre los diferentes estados constitucionales occidentales, son y pueden ser interpretados de distintas maneras. El trasfondo objetivo al que remiten las diferentes interpretaciones es la cultura nacional en la que se fundamenta el respectivo estado constitucional. Con otras palabras:

\footnotetext{
123 En lo concreto el contenido de la "cultura constitucional" puede ser ambivalente. La alta participación en las elecciones nacionales puede ser entendida como una característica particular de la cultura constitucional, que se encuentra impregnada del la "voluntad de poseer una Constitución" en el sentido que le otorga K. Hesse (también: H. P. Schneider, en: AöR fascículo 1, 1974, p. 64 ss. [68 ss.], pero también como señal de conflictos políticos 0 coerción política (cf. con relación a esta tendencia R. Dahrendorf, Für eine Erneuerung der Demokratie in der Bundesrepublik, 1968, p. 36 ss.).
} 
El mismo texto adquiere en las distintas culturas jurídicas un contenido diferente. La "interpretación específicamente cultural de la Constitución" refiere a los métodos y procedimientos, pero también a los "trasfondos" de esta interpretación.

Esta relatividad del contenido de los textos jurídicos no es un mal necesario, sino un asunto condicionado por la materia. La individualidad de una Constitución tiñe de distinta manera textos que parecieran presentar idénticos contenidos, es decir que les imprime una especificidad cultural $^{124}$.

Es por esto que la interpretación específicamente cultural de la Constitución puede reconocer mejor los "indicios" para el abordaje del tiempo. Los métodos para la interpretación de la Constitución han concedido al factor tiempo una más o menos encubierta centralidad en la explicación. En parte "absolutizan" ciertos "tiempos"125 particulares. La utilización flexible de los distintos métodos de la interpretación que realiza $H$. $E h m k e^{126}$ ha significado por esta razón un quiebre, aunque ha quedado sin responder con qué parámetros se combinarían finalmente

124 La comparación jurídica en el derecho público no ha tematizado hasta el momento lo específicamente cultural de manera metodológica (acerca de la comparación jurídica: J. H. Kaiser, H. Strebel, R. Bernhardt y K. Zemanek, en: ZaöRV 24 (1963), p. 391 ss., 404 ss., 431 ss. y también 452 ss.; J. M. Mössner, en: AöR 99 (1974), p. 193 ss.; véase también P. Häberle en: K. Vogel (ed), Grundrechtsverständnis und Normenkontrolle, 1979, p. 65 ss. -Discusión-). Esto sorprende, ya que en la discusión acerca de los derechos humanos es difícil reconocer que los textos jurídicos son comprendidos de maneras diversas y que -sin crear un problema de mala conciencia- también pueden ser comprendidos de diferentes maneras. Por cierto, hace tiempo se ha reconocido la relevancia del "ambiance" (D. Schindler) de la historia, etc. En mi opinión, aún resta contestar la pregunta acerca de cómo se expresan las diferencias específicamente culturales entre los pueblos en la interpretación jurídica. ¿Reúne contenidos específicamente culturales o actúa a través de métodos o es un método en sí mismo?

125 La interpretación histórica se despega del momento temporal de la creación de la norma jurídica (constitucional) - famosa y despreciada es la aún hoy en día propagada "teoría de la petrificación" en Austria-, el método objetivo de interpretación prácticamente se distancia del presente y en parte también del futuro, sin que esto se exprese siempre abiertamente. Un método de interpretación solamente orientado a consecuencias podría convertir al derecho constitucional en un derecho situacional.

126 H. Ehmke, VVDStRL 20 (1963), p. 53 (57 ss.), ahora en: íd., Beiträge zur Verfassungstheorie und Verfassungspolitik, 1981, p. 329 (332 ss.). 
los distintos métodos para la explicación. Al esclarecer los métodos de interpretación diversos recortes de lo que sucede culturalmente en el tiempo, es el enfoque científico cultural en la interpretación constitucional el que podría aportar un marco para la combinación de los métodos explicativos.

Derecho y ciencias jurídicas, legisladores y jueces no viven por sí solos. Dependen de los "materiales", de los "impulsos" y de las "sustancias", por ej. de nuevos elementos de justicia, nuevos reconocimientos y experiencias, pero también nuevas esperanzas e ideales, que dan cuenta de las leyes ya establecidas desde una perspectiva nueva o que obligan a defender los contenidos convencionales. Sabiendo que el derecho mismo es factor y expresión de la cultura pueden - "disciplinadas" en sus reglas del arte- tanto retrotraerse como adelantarse a los desarrollos culturales. Por cierto, esta "interpretación específicamente cultural de la Constitución" no es una "varita mágica" que resuelve repentinamente los problemas explicativos. Pero la interpretación constitucional sí gana una apertura y una vinculación no sólo a los movimientos, desarrollos y autoafirmaciones sociales y económicos, sino también culturales, que caracterizan una comunidad política ${ }^{127}$.

\section{Incursus II: La reanimación de las cláusulas republicanas: un ejemplo de procesos de expansión cultural de las Cons- tituciones}

A partir del ejemplo del principio constitucional "República" (Art. 20 inc. 1, 28 inc. 2 GG) se muestra cuán fuertemente se encuentra vinculado el derecho constitucional con los "procesos de expansión cultural", cuán dependientes son los procedimientos de interpretación jurídica de lo cultural y no primariamente jurídico: objetivamente y en lo personal; y cómo una determinación "jurídico formal" poco considerada cobra (nuevamente)

\footnotetext{
127 Un ejemplo es el pensamiento ecológico. Recién después del interés de la vanguardia espiritual de la sociedad, de filósofos, humanistas y artistas, intentan tomar parte las ciencias jurídicas: véase C. Sening, Bedrohte Erholungslandschaft, 1977, p. 80.
} 
vida con el "transcurso del tiempo", mejor dicho, es actualizada por el ambiente cultural pero también se transforma como parte de la (re)producción cultural y la recepción.

La cláusula republicana fue desatendida científicamente desde la fundación de la República Federal. A pesar de distintos intentos de reanimación a partir de la referencia a su vinculación con la "res publica" y "salus publica" ${ }^{128}$ prepondera por lo general en la teoría del estado la simple definición por la negativa: la República como la "no monarquía"129. En nuestros días llegaron impulsos del ámbito cultural- político- literario, que buscan otorgar una nueva, mejor dicho, positiva significación y "cooptar" el concepto: pensadores y poetas lograron aportes previos en este sentido. Recuerdo aquí las "Briefe zur Verteidigung der Republik" ("Cartas para la defensa de la República”), escritas no tanto por juristas ${ }^{130}$ como por literatos (por ejemplo H. Böll, N. Born, D. Kühn, H.-E. Nossack o M. Walser $)^{131}$, o los "Republikanische Reden" ("Discursos republicanos") (1979) de W. Jens. Recién después los juristas recordaron la riqueza de sentidos del concepto de República ${ }^{132}$. Trabajan ex post: conciente

128 K. Hesse, Grundzüge des Verfassungsrechts der BR Deutschland, $12^{\mathrm{a}}$ edición 1980, p. 50 ss., 110; $4^{a}$ edición 1970, p. 50 ss., 103; $1^{\text {a }}$ edición 1967, p. 50 ss., 103; P. Häberle, Öffentliches Interesse als juristisches Problem, 1970, p. 708, 728; íd., Verfassung als öffentlicher Prozess, 1978, p. 68, 198, 206, 487.

129 Cf. por ej. B. G. Jellinek, Allgemeine Staatslehre, $5^{a}$ reimpresión de la $3^{\text {a }}$ edición 1928, 1959, p. 711. El índice de materias de 74 columnas de: H. Krüger, Allgemeine Staatslehre, $2^{a}$ edición 1966 (1028p.) ni siquiera menciona la palabra clave "república".

130 Véanse las cartas de Ulrich Klug y Richard Schmid.

131 Editado por F. Duve, H. Böll y K. Staeck, 1977 (también la consiguiente controversia entre K. Sontheimer y J. Habermas, en: SZ 26-27/11/1977, ahora en: J. Habermas, Kleine politische Schriften I-IV, 1981, p. 387 ss.); cf. del mismo editor también el tomo: "Kämpfen für die sanfte Republik", 1980; también en otros escritos de esta línea editorial ha sido activado el tópico de la "república": cf. W. D. Narr (ed.), Wir Bürger als Sicherheitsrisiko. Beiträge zur Verfassung unserer Republik, 1977; véase también M. Güde, L. Raiser, H. Simon y C. F. Von Weiszäcker, Zur Verfassung unserer Demokratie, 4 republikanische Reden, 1978. Entretanto el concepto "de izquierda" ya es usual, cf. el título del tomo 1 de las palabras claves acerca de la "situación espiritual del tiempo", editado por J. Habermas, 1979: "Nation und Republik".

132 Cf. K. Löw, en: DÖV 1979, p. 819 ss.; J. Isensee, en: JZ 1981, p. 1 ss.; W. Henke, en: JZ 1981, p. 249 ss.; P. Häberle, en: FS H. Huber, 1981, p. 211 (237 ss.). 
o inconcientemente inspirados por la reproducción cultural. Por ello es tan importante el derecho constitucional cultural en tanto cuidado de lo creativo. La "República" es comprendida ahora en un sentido "liberal", "democrático" y "responsable". (Re)activada de esta manera, la "República" puede ser vivenciada por todos los intérpretes constitucionales de la sociedad abierta y materializada en todas las formas - como jurisprudencia y como meta educativa, jurídica y pedagógicamente.

Esta comprensión material de la República ya ha superado una primera prueba en Europa: Picasso había dispuesto en su testamento que el cuadro "Guernica" recién pudiera ser llevado a España cuando allí rigiera "la República". Esta condición fue interpretada con razón por los "administradores testamentarios" y herederos de Picasso como "cuando rijan nuevamente condiciones democráticas y de libertad", lo cual también puede ser el caso en una monarquía parlamentaria como en la España actual $^{133}$.

\subsection{4. "Libertad cultural" - Deberes fundamentales}

La "libertad cultural" es el concepto a través del cual la teoría del derecho fundamental encuentra vinculación con la problemática del tiempo a partir de la revisión de cuáles son los condicionamientos culturales (político-culturales) y específicamente culturales de la libertad jurídica formal y la dignidad humana, cómo se desarrollan culturalmente y se "materializan”. Los catálogos de los derechos fundamentales pueden ser

\footnotetext{
133 Cf. FAZ del 23/1/1981, p. 21 y del 2/3/1981, p. 23. La referencia a la Constitución como gran "oferta" (G. Heinemann) también puede ser fructífero para algunos de sus principios por separado. Conocemos ejemplos para el "renacimiento" de las proposiciones constitucionales, como las metas educativas y los "derechos sociales fundamentales" de las Constituciones de los Länder (con relación a esto, B. Beutler, Das Staatsbild in den Länderverfassungen nach 1945, 1973; P. Häberle, VVDStRL 30 (1972), p. 43 (90 ss.). Lo contrario también es habitual: el olvido de contenidos o mandatos constitucionales, por ejemplo los deberes fundamentales 0 el Art. 29 inc. 1 a.F. GG. Las Constituciones como "conjuntos de reglamentaciones jurídicas" no viven de sí mismas; más bien suelen ser la envoltura de sucesos sustancialmente más profundos de naturaleza cultural (lo político es solamente un aspecto).
} 
semejantes en exteriormente: la significación de sus contenidos recién se expresa en su contexto cultural ${ }^{134}$. Aquí cobra sentido la interpretación específicamente cultural de la Constitución.

¡No hay libertad sin cultura! El uso individual de la libertad se encuentra impregnado por incontables experiencias históricas y aseguramientos, es decir: el factor cultural- temporal también condiciona la libertad ${ }^{135}$. El jurista se halla aquí necesariamente ante los límites de su disciplina. No puede definir "lo cultural" en particular y depende por ello de los avances de las demás disciplinas. Por ello debe redactar las garantías de libertad cultural de manera suficientemente formal y amplia como para que al arte y a los artistas les quede suficiente espacio ${ }^{136}$. Se puede reconocer cuán fuerte es la transformación en los límites variables: la película "El silencio" de Bergman se encuentra hoy en día comprendida en la libertad del arte expresada en el Art. 5 inc. 3 GG, décadas atrás esto era negado o al menos discutido. La consecuencia son los esfuerzos por desplegar los contenidos de libertad que se pueden reconocer en el derecho constitucional cultural en el sentido de un concepto cultural abierto ${ }^{137}$. Esto también significa adjudicar al estado cultural la tarea de

\footnotetext{
134 La comparación de los derechos fundamentales solamente es posible como comparación intercultural, la comparación superficial de los textos solamente aporta primeros indicios. Sólo el contexto cultural muestra la significación real de los derechos fundamentales. Un abordaje desde las ciencias sociales únicamente, sería demasiado acotado. Al considerar a todos los derechos fundamentales como "derechos fundamentales sociales en sentido amplio", se torna más importante su dimensión cultural más profunda: también en la sucesión de generaciones y en la transformación de los textos constitucionales de un pueblo.

135 La creciente individualización y privatización del poder de disposición sobre el tiempo por ejemplo a través de la reducción de la jornada laboral, jornadas flexibles, trabajos part time, por un lado, o por la ausencia de una sujeción a un momento temporal concreto, por ejemplo a través de eventos culturales grabados en casettes, discos, películas o las futuras técnicas de video, por el otro lado - actualizan cada vez más las ataduras culturales de la libertad.

136 Así el planteo de W. Knies, Schranken der Kunstfreiheit als verfassungsrechtliches Problem, 1967.

137 Con relación a esto, P. Häberle, Kulturpolitik in der Stadt - ein Verfassungsauftrag, 1979, p. 34 ss., 37, 57 ss.; íd., Kulturverfassungsrecht im Bundesstaat, 1980, p. 13 ss.
} 
efectivizar a su manera los derechos fundamentales culturales en el sentido de los derechos de participación culturales y en especial de efectividad procesal ${ }^{138}$.

Las garantías legales para la libertad cultural no generan por sí solas libertad cultural, pero son la condición para que ésta sea posible: el espacio de libertad garantizado por los derechos fundamentales para los individuos, abre la comunidad política como comunidad cultural a todos aquellos procesos y desarrollos, descubrimientos y obras que hacen a su identidad. Los textos clásicos y su nueva (re)actualización a través de la interpretación, descubrimientos científicos, obras de arte de todo tipo, filosofías políticas e innovación económica son consecuencia y expresión de una compleja libertad "cultural" entendida en el sentido más amplio ${ }^{139}$. Al mismo tiempo la conducen hacia "nuevas orillas". Vista en la línea del tiempo, la libertad culturalmente efectivizada de $J$. Beuys tiene incidencia sobre la garantía legal de libertad: ésta se amplía. La petición por la "libertad de pensamiento" manifestada culturalmente en el "Don Carlos" de F. Schiller, se torna un texto clásico con efectos a largo plazo en muchas épocas constitucionales. La pregunta de B. Brecht "todo el poder del estado parte del pueblo, ¿pero hacia dónde se dirige?" es una "espina" en el cuerpo de toda teoría democrática. En síntesis: lo nuevo se origina de la libertad cultural, "cuaja"

\footnotetext{
138 Un punto neurálgico es la pregunta acerca del derecho a subvención por parte de los teatros privados.

139 Los procesos de crecimiento cultural se desarrollan a través de un juego de ida y vuelta desde la libertad „potencial“, pasando por la la libertad "realizada” o mejor dicho resultados culturales de la libertad, hasta obras a partir de las cuales es posible, y se torna necesaria, una nueva libertad individual, a la que además debe aspirarse (aún con la posibilidad de fracasar). La libertad cultural es -contemplada en la línea del tiempo- obra de muchas generaciones, vista "transversalmente" es producto de muchos círculos y grupos diferentes de un pueblo o intérpretes de la Constitución. Vista desde la condición individual de un pueblo la libertad está garantizada por las "objetivaciones" y "materializaciones", es decir, resultados, que su ejercicio individual puede desencadenar. Los actuales esfuerzos en torno a formas culturales "alternativas" no son una contradicción, sino más bien la confirmación de la aquí expresada vinculación entre cultura y libertad.
} 
formando una porción de cultura (del derecho fundamental) ${ }^{140}$ e impulsa el desarrollo de la misma.

Un proceso de desarrollo de este tipo también ilustra el ejemplo de los deberes fundamentales. Con referencia a estos falta aún una teoría constitucional diferenciada. Con vistas a los actuales desafíos y falencias, discutidos como "límites del estado social", y ante nuevos reconocimientos de la solidaridad como condición para la comunidad humana (jla revolución francesa también exigía la "fraternidad" ${ }^{414}$ !), se formula hoy la pregunta acerca de si la reconsideración de los deberes fundamentales no será una cuestión de tiempo ${ }^{142}$. Probablemente el deber fiduciario que corresponde a la Constitución en cuanto a los bienes culturales y hacia las futuras generaciones, también deba ser construido desde los deberes fundamentales del ciudadano. La dignidad humana se constituye -como toda libertad cultural- a partir de los logros de generaciones previas y también obliga al respeto por las venideras. Quizás ya nos encontremos aquí y ahora ante el "Renacimiento" de los deberes fundamentales ${ }^{143}$.

140 Expresión de la "libertad cultural" es la "cultura del derecho fundamental", es decir, la parte de la "cultura constitucional" referente a los derechos fundamentales y con ello una parte de la constitución ${ }^{* *}$ no jurídica de la comunidad política. La cultura de los derechos fundamentales es sólo en parte obra de textos constitucionales jurídicos y dogmatismo jurídico, más bien se desarrolla a partir de tradiciones republicanas, tal como se muestran en el funcionamiento de la opinión pública, en la ética profesional de los periodistas (cf. instituciones como el Consejo de Prensa alemán) o en "reglas de juego" de los medios masivos de comunicación. Cf. para ello P. Häberle, Kommentierte Verfassungsrechtsprechung, 1979 , p. 88 ss.

141 H. Krüger, Brüderlichkeit - das dritte, fast vergessene Ideal der Demokratie, en: Festgabe für T. Maunz, 1971, p. 249 ss.

142 Véase ahora R. Stober, Grundpflichten und Grundgesetz, 1979.

143 De esta manera se harían efectivas las alusiones meramente verbales a la libertad o en el mejor de los casos la formulación "idealista" de la parte vinculante de la libertad, como ya se muestra en el desarrollo de la relación del derecho administrativo: cf. P. Häberle, Das Verwaltungsrechtsverhältnis - un esbozo de estos problemas puede encontrarse en: íd., Die Verfassung des Pluralismus, 1980, p. 248 ss.

** N. d. T.: El autor hace aquí un juego de palabras entre Verfassung (Constitución) y (Ver) Fassung (expresión, versión). 


\section{La Constitución como contrato generacional para la protección de los bienes culturales de la posteridad - expuesto a partir de ejemplos de la actualidad: protección del medio ambiente, límites del endeudamiento del estado como precedente de "un tiempo y una cultura (constitucional)"}

\subsection{El enfoque de la teoría constitucional}

El abordaje del problema del tiempo en el derecho constitucional es puesto a prueba hoy, a partir de dos interrogantes de gran importancia política: en la indagación acerca de los límites del endeudamiento estatal y de la energía atómica. Como el derecho constitucional "positivo" aporta aquí inicialmente pocos elementos relacionados -exceptuando el Art. 115 inc. 1 párrafo 2 GG y también el Art. 2 inc. 2 GG-, esto se constituye en un reto para la teoría constitucional.

La sensibilización respecto a la dimensión temporal no se da aquí solamente con vistas al análisis o la estimulación de la transformación, sino en sentido inverso también con el objetivo de la preservación de una específica "herencia" cultural y en interés de las futuras generaciones ${ }^{144}$. Para ellos debe conservarse la tradicional libertad de configuración política: su democracia ${ }^{145}$, su derecho de autodeterminación, sus derechos fundamentales, podrían ser tocados en lo sustancial si nosotros, la actual generación, vía el endeudamiento estatal por impuestos, viviésemos a costilla de las futuras generaciones; su entorno y con ello las condiciones de su dignidad humana, su naturaleza y cultura, su humanidad y libertad se verían

\footnotetext{
144 Notable resulta el aporte de F. Vilmar, en: Die neue Gesellschaft 28 (1981), p. 458 ss., quien propone ubicar el aseguramiento de la existencia humana en el primer lugar de la escala de valores y exige una nueva "ética de la preservación, conservación, reparación y no del progreso o del perfeccionamiento". Véase también H. Jonas, Das Prinzip Verantwortung, 1980, quien pide evaluaciones acerca del número de inventos humanos que la naturaleza aún es capaz de soportar y exige una "ética de la responsabilidad remota".

145 La relación entre deudas estatales y condiciones de vida en la democracia es analizada -a partir de los aportes de J. Buchanan y R. Wagner- por G. Püttner, Staatsverschuldung als Rechtsproblem, 1980, p. 9, 11.
} 
afectados en lo existencial, si el almacenamiento de basura atómica implicara inesperados peligros para sus vidas ${ }^{146}$. De un "efecto anticipado" de bienes jurídicos constitucionales, cuyos destinatarios aun no han nacido ${ }^{147}$, se desprende hoy un deber constitucional relativo a la preservación y al desarrollo de la diversidad de la naturaleza y la cultura y al establecimiento del correspondiente marco. La frecuentemente evocada preservación de la "herencia de la humanidad" también debe ser abordada con seriedad por el estado constitucional: con la fuerza de un mandato constitucional.

La teoría constitucional aún se encuentra poco preparada para la protección cultural y natural de las generaciones en la dimensión temporal. Recién en nuestros días es comprendido el "riesgo potencial de la energía atómica en el tiempo". Éste surge del peligro de posibles consecuencias tardías resultantes de la sobreexposición a la radioactividad, por la larga vida de los desechos radioactivos y por el incalculable "riesgo potencial que implica el tratamiento de los desechos nucleares"148 a lo largo del tiempo.

El endeudamiento del estado surge, visto en el tiempo, como una oculta estrategia impositiva a cargo de las futuras generaciones. Su protección debería "anticiparse" en el marco de la prohibición de los excesos: la actual generación no debe vivir en la abundancia a costa de las futuras generaciones. Por supuesto que el endeudamiento actual del estado también puede

\footnotetext{
146 La "cuestión de la cultura" es la expresión intensificada de la dignidad personal realizada, participativa y no por último alcanzada con esfuerzo. Ni está "a disposición" del estado, ni puede ser comprendida en sentido meramente instrumental para la dignidad humana.

147 Los "aún no nacidos" se convierten cada vez más en destinatarios de la literatura y del derecho: cf. por ej. el mensaje de Louise Weiss "a los aún no nacidos" (1980) y el voto del BVerfG a favor de los aún no nacidos en § 218- Resolución (E 39, 1).

148 Con respecto a esto véase C. Degenhart, Kernenergierecht, 1981, p. 162 ss., con una argumentación sobre el Art. 2 inc. 2 GG. Acerca de la "protección de la posteridad" a partir del GG y de las "dimensiones temporales de la responsabilidad jurídica estatal" véase $H$. Hofmann, Rechtsfragen atomarer Entsorgung, 1981, p. 259 ss., 262 ss.
} 
posibilitar y asegurar la existencia de las futuras generaciones, por ejemplo, en las así llamadas "inversiones a futuro". Pero esto es solamente un aspecto. En un determinado momento el endeudamiento del estado deja de ser una inversión a futuro para convertirse en una carga ("bipotecaria") para el futur ${ }^{149}$.

En mi opinión, sólo un enfoque más profundo, justamente el científico cultural, puede incorporar ya hoy a la "posteridad" de tal manera en el círculo y en el ámbito de responsabilidades del estado constitucional y sus leyes, mejor dicho de los políticos e intérpretes constitucionalistas, que las condiciones de vida materiales e ideales de esta posteridad se encuentren previamente aseguradas. En la combinación del pensamiento fiduciario con la dignidad humana se halla la (auto)responsabilización ética por la protección de las futuras generaciones. La "Constitución" debe pensarse desde un inicio teniendo en cuenta y asumiendo la responsabilidad por las futuras generaciones del pueblo constitucionalista, no importando cómo se realiza esto desde el punto de vista técnico legal (por ej., a través de un contrato a favor de terceros, de los aún no nacidos). La Constitución de hoy ya lleva en sí misma una parte de la Constitución del futuro. Ella es responsable por esta específica Constitución. Si se abocara solamente al hoy, si se justificara sólo ante el hoy, sería tan egocéntrica como fragmentaria. La "apertura de la Constitución" también debe tratarse seriamente por cuanto en el presente se gestan las garantías para un futuro abierto: a esto pertenece la discusión en torno a los límites del endeudamiento del estado y la protección de las futuras generaciones ante los imprevisibles riesgos atómicos. El futuro abierto y la sociedad abierta deben darse en conjunto.

\footnotetext{
149 Específicamente H. Ehmke, Grenzen der Verfassungsänderung, 1953, p. 130, ahora en: Ídem, Beiträge zur Verfassungstheorie und Verfassungspolitik, 1981, p. 129 (con relación al derecho presupuestario y endeudamiento del estado): “De la misma manera debe contemplarse como anticonstitucional una sobrecarga tal, que ponga en peligro la libertad de la vida política de las futuras generaciones".
} 


\subsection{En concreto: Interrogantes acerca del cuidado del medioambiente en la era de la energía atómica}

La "Constitución como contrato", que se renueva bic et nunc pero también de manera continua a lo largo del tiempo ${ }^{150}$, es el primer aspecto. Puesto en práctica desde hace poco en Polonia, la Constitución como contrato quizás sea una "invariante cultural" en el sentido de Kolakowski ${ }^{151}$, una tesis del como si, para poder vivir y sobrevivir en comunidad ${ }^{152}$. El contrato generacional interpretado de manera dinamizada -para el seguro social $^{153}$, un bien conocido entramado" ${ }^{154}$ _ podría contener

150 La expresión "plebiscite de tous les jours" de A. Renan está pensada casi únicamente desde el punto de vista de la soberanía del pueblo, debería reformularse como pensamiento contractual: en el sentido de un contrato social que se renueva constantemente, que se fundamenta en el Art. 1 GG (dignidad humana) y se expresa en el derecho electoral común; cf. también R. Bäumlin, Staat, Recht und Geschichte, 1961, p. 46 ss.

151 L. Kolakowski, In der Sackgasse der Kulturanthropologie, en: Merkur 1980, p. 1188 ss.

152 Con respecto a la Constitución como contrato véase mi presentación en Augsburgo en 1978: Verfassungsgerichtsbarkeit als politische Kraft, en: P. Häberle, Kommentierte Verfassungsrechtsprechung, 1979, p. 438 ss.; véase también P. Saladin, en: AöR 104 (1979), p. 345 (372 ss.). El contrato social o generacional es una "ficción" del derecho constitucional tan necesaria como útil, en especial porque en la realidad actual tienen lugar muchos momentos contractuales constitucionales. Sea como sea, es la presente generación la que debe someterse a los límites del autocontrol en vistas de la futura generación. El modelo de contrato puede ofrecer protección contra la arbitrariedad.

153 Cuan cercano puede estar el futuro en el derecho, lo muestra el seguro social y la amenazante cuota de sobrecarga. Ya hoy se deben considerar cifras referidas al año 2030: porque entonces será la generación venidera la que sostenga a la actual generación en lo previsional. Ya hoy en día se estiman montos con relación a los cuales deben orientarse la política y el derecho, aunque éstos tengan que ser revisados y recalculados continuamente a lo largo del tiempo. El contrato generacional es un contrato social "a lo largo del tiempo", un contrato social dinamizado. En todo caso comprende toda la profundidad del pasado, presente y futuro de un pueblo y muestra que el factor tiempo condiciona problemas básicos del derecho constitucional de manera existencial: véase también W. Schmitt, en: DVBI. 1979, p. 873 (875 ss.); además: T. Maunz/H. Schraft, en: Die Sozialversicherung der Gegenwart, anuario, tomo 7 (1968), p. 5 (9). En relación a la figura del "contrato generacional" también BVerfGE 53, 257 (292 ss., 295); véase también E 53, 164 (177): evitar la sobrecarga de las "generaciones económicamente activas".

154 Cf. ya en K. Mannheim, Das Problem der Generationen (1928), en: Ídem, Wissenssoziologie, $2^{\text {a }}$ edición, 1970, p. 509 ss. 
buenos argumentos extraídos de la teoría del contrato social de J. Rawls adaptados a nuestros tiempos ${ }^{155}$. Se presupone que una de las partes contratantes es la próxima generación, al menos se debe trabajar en base a esta "ficción"156. A la vez que se debe intentar establecer límites a las reformas constitucionales para vincular a la futura generación (cf. Art. 79 inc. 3 GG), también se debe liberar a esta futura generación, por lo cual no se la debe cargar con demasiados problemas ambientales y debe existir un autocompromiso (también vía deberes fundamentales) con y en la actualidad. Concretamente: no deben desencadenarse riesgos atómicos ${ }^{157}$ impredecibles para las futuras generaciones.

Este enfoque constitucional, mejor dicho de la teoría constitucional, encuentra en lo cultural su fundamentación y "elevación”. La Constitución debe transmitir bienes culturales - ¡esto también incluye a la naturaleza! En una serie de Constituciones no es casual que se establezcan vinculaciones entre la cultura $y$ la naturaleza en el texto ${ }^{158}$.

\footnotetext{
155 J. Rawls, Eine Theorie der Gerechtigkeit, 1979, en especial p. 27 ss.

156 El jurista trabaja habitualmente con ficciones, cf. por ej. F. Wieacker con respecto al "segundo lógico", en: FS Eric Wolf, 1962, p. 421 ss.; detiene el "reloj" en los gremios de la Unión Europea en Bruselas. Véase también el voto en disidencia de Geller, Rupp, BVerfGE 31 , 334 ss.; P. Häberle, Comentarios en DÖV 1981, p. 809 ss.
}

157 El BVerfGE 49, 89 (137 ss.) ya considera a aquellas regulaciones cuya implementación podría conducir a importantes daños constitucionales como potencialmente anticonstitucionales (141 ss.) Esta decisión acepta sin embargo el así llamado "riesgo residual" más allá del umbral de la "razón práctica" (143), porque la probabilidad de que se produzca un daño es prácticamente nula "en el actual estadío de desarrollo de la ciencia y la técnica" (143). Este riesgo residual se refiere solamente a la aprobación de las centrales atómicas- la pregunta (aún sin respuesta) acerca del tratamiento de los residuos atómicos no fue cerrada, más bien fue ("por ahora") postergada, haciendo referencia a una "reformulación" por parte de los legisladores. La - jirreversible! - sobrecarga de las futuras generaciones con nuestros desechos atómicos por siglos, al servicio de unas pocas décadas de crecimiento, se torna difícil de justificar si se considera a la Constitución (también) como un contrato generacional, mientras que a los aún no nacidos se les obstaculiza la ponderación de su propio riesgo, cf. R. Spaemann, en: Scheideweg 9 (1979), p. 476 (488 ss.).

158 Cf. Art. 150 inc. 1 WRV (Constitución de Weimar): Ios monumentos artísticos, históricos y de la naturaleza y el paisaje gozan de la protección y del cuidado del estado. Similar es el Art. 141 inc. 1 párr. 1 de la Constitución de Baviera y el Art. 40 inc. 1 párr. 3 de la Constitución 
La naturaleza y la cultura son bienes transformados por el hombre y continuamente influenciados por los cambios; ambos se encuentran específicamente vinculados - tanto en la historia de las ciencias humanas como de las ciencias sociales. Ante la amenaza y la "escasez" de la naturaleza, esta relación sale a la luz en la actualidad de manera renovada: hoy la protección de la naturaleza significa también protección de la cultura; el entorno natural y cultural son en este sentido un único entorno ${ }^{159}$. Con el suceder de las generaciones, la protección de la naturaleza como "bien cultural" se volvió una tarea sustancial para el estado cultural (cf. Art. 3 Constitución de Baviera). Específicamente: en lo referente a la preservación de la naturaleza como sustrato y condición para el desarrollo de la vida de las generaciones futuras, ésta se encuentra bajo el estatuto de la protección de monumentos ${ }^{160}$; existe una pertenencia "de mayor importancia que la libertad: la integridad de aquella naturaleza en cuyos nichos ecológicos se encuentran la vida y la libertad" (R. Spaemann) ${ }^{161}$. El estado constitucional debe ocuparse de lo que para él es "sustancial". A la herencia "cultural" y "natural" también corresponde la transmisión del espacio vital, más específicamente del entorno, a lo largo de las generaciones $^{162}$.

de Rheinland Pfalz, el 34 inc. 2 de Saar. ¡En el Art. 62 de la Constitución de Hessen, en lo restante prácticamente idéntico, se reemplaza el concepto de "naturaleza" por el de "cultura"! El Art. 18 inc. 2 Constitución de Nordrhein Westfahlen protege los monumentos culturales, históricos y artísticos, el paisaje y los monumentos de la naturaleza. El Art. 9 inc. 2 de la Constitución Italiana (1947): "Ella (ref. a la República) protege el paisaje y la herencia histórica y artística de la Nación".

159 Significativo es el Art. 24 inc. 1 párr. 1 de la Constitución Griega de 1975: “La protección del entorno natural y cultural es un deber del estado".

160 Con relación al "olvidado factor tiempo" en la explotación de las materias primas de la tierra sin horizonte temporal: H. Gruhl, Ein Planet wird geplündert, 1978, p. 91 ss. Una postura crítica ante el "reclamo ecológico" se encuentra especialmente en A. Mohler, Der Traum vom Paradies, 1978.

161 R. Spaemann, en: Scheideweg 9 (1979), p. 476 (496).

162 Cf. P. Häberle, VVDStRL 38 (1980), p. 340 ss. (Discusión). También es posible argumentar en un sentido específicamente constitucional de la siguiente manera: la Constitución tiene 
En la democracia liberal el pueblo no tiene un poder ilimitado de disposición sobre la herencia que ha recibido y que le ha sido encomendada. Sólo posee una especie de "fideicomiso"163 sobre los bienes naturales y culturales: debe entregarlos a la posteridad; la cual también tiene que poder vivir en condiciones de libertad política y cultural, y en democracia ${ }^{164}$. El "pueblo" es, también en la dimensión temporal, una fuerza pluralista. De esto surgen compromisos y responsabilidades constitucionales.

En el plano de los derechos fundamentales actúan limitaciones en un doble sentido. Derechos fundamentales como en el Art. 2 inc. 2 GG (protección de la vida y de la salud) protegen "anticipadamente" ya desde ahora a los aún no nacidos ${ }^{165}$ - así como el Art. 2 inc. 2 GG protege a los aún no nacidos en el marco de la discusión en torno al $\S 218 \mathrm{StGB}^{166}$. Pensado desde el presente, esta protección se refuerza por los deberes fundamentales: al ciudadano actual - cuya biografía individual se halla vinculada a la biografía cultural de su pueblo - se le plantea

la tarea de proteger ante un abuso estatal o social del poder. Este pensamiento debe ser considerado en la dimensión temporal: la generación aún no nacida, el "pueblo en gestación", ya hoy es objeto de la protección del derecho constitucional. Al menos desde el enfoque cultural ampliado es posible argumentar de esta manera. Existe una especie de "garantía de vida" para el pueblo en la secuencia generacional. Como pueblo cultural sólo puede sobrevivir bajo la existencia de la tradición cultural.

163 Plásticamente se vinculan en el preámbulo de la Constitución de Baden (1947) la historia, el presente y el futuro en el Treuhandgedanken (pensamiento fiduciario): “...el pueblo de Baden, como agente fiduciario de la transmisión de la cultura de Baden y animado por la voluntad de reestructurar a su estado con espíritu democrático según los principios de la ley moral cristiana y de la justicia social, se ha otorgado la siguiente Constitución". En general acerca de la dimensión temporal en los preámbulos véase mi clase magistral dictada en Bayreuth, en: FS Broermann (nota 19).

164 No nos referimos aquí al planteo de una garantía "ingenua" del statu quo de naturaleza y cultura. Ambas son demasiado cambiantes, aunque igualmente deben establecerse condiciones mínimas.

165 En cuanto a la "ampliación del radio de acción y garantía de los derechos fundamentales": P. Häberle, VVDStRL 30 (1972), p. 43 (69 ss.).

166 Cf. BVerfGE 39, 1. Una contribución a la argumentación también se encuentra en el Art. 125 inc. 1 párr. 1 de la Constitución de Baviera; "niños sanos son el bien más preciado de un pueblo". 
un deber fundamental (¡Art. 1 inc. 1 párr. 1 GG!) relativo al respeto por la vida y la integridad física del ciudadano del mañana ${ }^{167}$. Este deber fundamental basado en la teoría del contrato no solamente es de naturaleza moral y retórica, se torna una obligación jurídica. La literalmente existencial solidaridad - tanto natural como cultural- del ciudadano de un pueblo, no es solamente una cuestión del hoy y en el hoy, también es una cuestión en la sucesión generacional.

Las puntuales competencias del jurista relativas a la protección de los monumentos y de la naturaleza (por ej. Art. 74 inc. 24, 75 inc. 3 GG; Art. 141, 83 inc. 1, al final, de la Constitución de Baviera) pueden contribuir a formular esta cuestión. Contemplado a la luz de una interpretación material (positiva) de las competencias ${ }^{168}$, la Constitución se propone garantizar y promover la conciencia acerca de la protección de monumentos, paisajes, naturaleza y medioambiente como tareas culturales permanentes. Se prohíbe de esta manera la puesta en peligro de un medioambiente por los desechos atómicos.

En resumen, se da lugar a que los daños ambientales que puedan afectar a futuras generaciones ya boy en día se encuentren limitados: desde la cultura constitucional. Dónde se deben establecer específicamente, continúa siendo una discusión. Que, sin embargo, deben ser establecidos, debería ser evidente. La pretensión de eternidad del GG en el Art. 79 inc. 3 GG ha dado un viraje con relación a estos nuevos límites para la actuación en el estado constitucional; éste le otorga una nueva legitimación.

\subsection{En concreto: Límites del endeudamiento del estado}

Una última observación acerca del endeudamiento del estado: se trata de un asunto discutido para la economía nacional.

\footnotetext{
167 Véase también la apelación a la "conciencia generacional" en H. Gruhl, Ein Planet wird geplündert, 1978, p. 231 ss.

168 Cf. H. Ehmke, VVDStRL 20 (1963), p. 53 (89 ss.), ahora en: Ídem, Beiträge zur Verfassungstheorie und Verfassungspolitik, 1981, p. 329 (360 ss.); P. Häberle, Öffentliches Interesse als juristisches Problem, 1970, p. 468 ss., 618, 666 ss.; C. Pestalozza, en: Der Staat 11 (1972), p. 161 ss.
} 
La historia de los dogmas y la teoría contemporánea pendulan entre dos textos clásicos: las palabras de Ricardo acerca de que "el endeudamiento público es uno de las más terribles flagelos que han sido ideados para castigar a la nación” y la afirmación de Lorenz von Stein: "un estado sin deudas públicas o está haciendo demasiado poco o exige demasiado de sus contemporáneos" ${ }^{\prime 69}$. Probablemente sea el término medio el correcto $^{170}$, en especial porque las Constituciones democráticas no deben comprometerse con una sola teoría científica. Las deudas públicas sirven -como el seguro social- a la distribución de oportunidades $y$ de cargas entre generaciones y "entre los tiempos" ${ }^{171}$. Como no es posible definir un límite absoluto y cuantificable para el endeudamiento estatal independiente de tiempo y espacio, se torna aún más importante la discusión con relación al establecimiento de un límite al endeudamiento concreto. Éste se ha alcanzado cuando la carga impositiva de los ciudadanos es a largo plazo tan alta que "el pago de los intereses resultantes de nuevos endeudamientos prácticamente no precisa ser financiado por un aumento impositivo, sino principalmente a partir de ahorros..."172.

169 Citado por R. Hickel, en: K. Diehl/P. Mombert (ed.), Das Staatsschuldenproblem, 1980, p. VI.

170 Cf. R. Hickel, ebd., p. XXXIX: "Necesidades y límites del endeudamiento público". De diferente manera también E. Lang/W. A. S. Koch, Staatsverschuldung - Staatsbankrott, 1980. Véase también la postura intermedia del Instituto Alemán para la Investigación Económica (FAZ del 2/7/1981, p. 11), que advierte tanto ante "esfuerzos político-económicos en dirección expansiva" como también ante una reacción desmesurada frente a la solicitud de un recorte radical del déficit estatal. Sin embargo, véase también el título del trabajo de J. Starbaty, FAZ del 14/3/1981, p. 13: "Los bienes públicos de la sociedad se están consumiendo".

171 En cuanto a la discusión americana acerca de la "inter-generation equity": H. Hoppe, Probleme der öffentlichen Verschuldung, Institut Finanzen und Steuern e. V., cuaderno 115, 1977, p. 81 ss.

172 H. Hoppe, ebd., p. 58. Püttner, ebd., p. 11 y otros desarrollos a partir del principio básico "poder temporal", según el cual el legislador elegido sólo puede disponer de los ingresos definitivos para el período de su función y no especular con los ingresos de los futuros funcionarios. El estado de la discusión es resumido por K. Stern, Das Staatsrecht der BR Deutschland, tomo 2, 1980, p. 127 ss., con otras referencias; además: P. Schaal, Thesen zur Staatsverschuldung in der BR Deutschland, en: BB 1981, p. 1 ss.; H. H. von Arnim, 
¿Cómo se puede justificar un límite semejante en el contexto de un estado constitucional? En mi opinión, con la ayuda del "argumento del tiempo". La democracia, entendida tal como la define Theodor Heuss como poder temporal ${ }^{173}$, intenta en el derecho constitucional presupuestario y financiero limitar el poder a partir de un riguroso "régimen del tiempo"174 y asegurar de esta manera la libertad política. Además del control del poder que ya se realiza a través la limitación del período legislativo parlamentario a cuatro años, le sirven a esta meta los siguientes institutos "formales", que descomponen la microdimensión "tiempo en el derecho constitucional" en unidades aún más pequeñas ("medidas temporales") que los períodos de cuatro años: la determinación del presupuesto "según uno o más ciclos de ejercicios contables" (Art. 110 inc. 2) ${ }^{175}$, la detallada normalización de la admisibilidad de efectivizar gastos antes de la aprobación del presupuesto, la estricta reglamentación de un derecho presupuestario provisional (Art. 111 GG) ${ }^{176}$, la obligatoriedad de la rendición de cuentas del Ministro de Hacienda en el transcurso del ejercicio económico siguiente y de la auditoría anual por parte del Tribunal Federal de Cuentas (Art. $114 \mathrm{GG})^{177}$.

Grundprobleme der Staatsverschuldung, en: BayVBI. 1981, p. 514 ss.; G. Brenner, C. E. Haury, E.-M. Lipp, Staatsverschuldung und Verfassung, en FinArch 38 (1980), p. 236 ss.

173 La democracia como "poder temporal" por cierto también se puede denominar "poder en el tiempo". Sin embargo esto no debe significar que la actual generación concientemente provoque cargas prácticamente intolerables para la futura generación a través de hechos irreversibles y le "quite" de esta manera el futuro.

174 Completamente bajo el estricto régimen del tiempo también se hallan las normas paralelas en los estados constitucionales más nuevos: cf. Art. 78 Constitución de Grecia (1975), que en el inc. 2 establece la prohibición de efectos retroactivos para las leyes relativas a impuestos y cargas financieras; el Art. 79 inc. 5 de la misma Constitución prevé una limitada prórroga del antiguo presupuesto ante la ausencia de uno nuevo. Cf. también Art. 134 Constitución de España (1978).

175 Véase también el uso del concepto de "períodos" en el Art. 110 inc. 2 párr. 2 GG.

176 Asimismo Art. 80 Constitución de Baden-Württemberg; Art. 140 Constitución de Hessen.

177 Cf. con H. Ehmke, Grenzen der Verfassungsänderung, 1953, p. 129, ahora en: Ídem, Beiträge zur Verfassungstheorie und Verfassungspolitik, 1981, p. 128: "Un momento esencial 
Esta sensibilidad temporal expresamente normalizada ${ }^{178}$ y el pensar en "pequeñas unidades temporales" es un primer indicio de que en el ámbito presupuestario y financiero el estado constitucional sólo quiere otorgar la libertad disposicional para algunos aspectos y por un tiempo determinado -es decir de manera limitada-. Detrás de la, en apariencia, meramente formal "dominación temporal", se esconde un pensamiento material ${ }^{179}$ (una parte de la división de poderes y el aseguramiento de la libertad política). La postura moderada de la Constitución, originada en la responsabilidad democrática, persiste, porque las deudas en tanto "acontecimientos negativos" son más difíciles de deshacer que cualquier ley. Desde el aspecto material ${ }^{180}$, son

para el aseguramiento de la libertad política en la sucesión generacional es el derecho presupuestario, porque los gastos por lo general son aprobados por el plazo de un año y no por períodos temporales incontrolables".

178 El estricto "régimen" del tiempo también puede observarse en las Constituciones de los Länder alemanes (cf. por ej. Art. 107 inc. 2 Const. Saar; Art. 141 hasta 144 Const. Hessen).

179 Con razón afirma G. Püttner, Staatsverschuldung als Rechtsproblem, 1980, p. 12, que la obligación del balance presupuestario anual "no es solamente una cuestión secundaria". 180 Desde un enfoque comparado, o mejor dicho histórico, pueden reconocerse en las actuales reglamentaciones del derecho presupuestario y financiero constitucional, elementos para el disciplinamiento del estado constitucional con relación al endeudamiento estatal. Según Art. 115 inc. 1 GG (asimismo Art. 84 párr. 2 Const. de Baden-Württemberg; Art. 54 párr. 2 Const. de Niedersachsen; Art. 117 párr. 2 Const. Rheinland-Pfalz), los ingresos a través de créditos no deben superar la suma estipulada para inversiones prevista en el presupuesto. El derecho más antiguo fue más estricto: ya el Art. 115 párr. 1 GG versión antigua- vigente hasta 1969 (con respecto a esto G. Püttner, Staatsverschuldung als Rechtsproblem, 1980, p. 17 ss.) - permitía la obtención de créditos "sólo ante la necesidad extraordinaria y en regla general sólo para gastos promocionales". Con esto se encontraba en consonancia con algunas Constituciones alemanas aún vigentes (Art. 75 inc. 2 Const. Berlín permite empréstitos "sólo para solventar una necesidad extraordinaria, en regla general sólo para inversiones cuyo valor sea permanente"; asimismo Art. 141 Const. Hessen; Art. 46 Const. Schleswig-Holstein). Art. 82 Const. Baviera contiene la cláusula de la "necesidad extraordinaria". Muchas Constituciones "superadas" concordaban con la versión antigua del Art. 115 GG: cf. Art. 87 WRV: "sólo ante la necesidad extraordinaria y en regla general sólo para gastos promocionales". Este modelo también es seguido por las Constituciones de Alemania del este después de 1945 (citado en B. Dennewitz, Die Verfassung der modernen Staaten, tomo 2, 1948): Art. 57 Brandenburgo; Art. 84 Mecklenburg-Vorpommern; Art. 83 párr. 1 Sachsen-Anhalt; Art. 66 inc. 1 Thüringen. De las ya derogadas Constituciones de los Länder del sudoeste alemán se correspondía el Art. 102 de la Constitución de Baden (1947) con los principios del Art. 87 WRV. 
además aquellas normas constitucionales que buscan delimitar el poder financiero del estado, las que vinculan la obtención de créditos con precondiciones como la "necesidad extraordinaria", "fines promocionales", "valores permanentes", entre otros ${ }^{181}$. También corresponden aquí las condiciones limitadas bajo las cuales, en caso de una inesperada e impostergable necesidad en el sentido del Art. 112 GG, se aceptan gastos que excedan el límite fijado en el presupuesto ${ }^{182}$; asimismo el principio de la preservación del "patrimonio básico" del Estado (Art. 81 Constitución de Baviera).

Este estricto "régimen temporal" fue reivindicado por el estado constitucional democrático a causa del peligro que significa un manejo financiero incontrolado y a largo plazo; más aún, el manejo financiero debe ser limitado especialmente en la dimensión macro de "la Constitución en el tiempo": en beneficio de la libertad política.

Finalmente es pertinente el principio constitucional del estado prestacional: un estado constitucional extremadamente endeudado en el largo plazo, es decir en la sucesión generacional, no puede resolver sus responsabilidades en cuanto a la gestión eficaz ni al cumplimiento del derecho fundamental cuando su obligación de saldar los intereses de la deuda le quita toda libertad de acción democrática. Su capacidad de cumplir con los compromisos públicos ${ }^{183}$ debe ser mantenida tanto como la libertad política. Esto puede implicar la toma de deuda pública

\footnotetext{
181 ¡Estas cláusulas de necesidad son a su vez un ejemplo de normas constitucionales que ya implican en sí mismas una transformación! (véase también Art. 112 GG).

182 Cf. BVerfGE 45, 1; con respecto a la "presión temporal": ebd. p. 36 ss.; también K. Stern, en: FinArch 37 (1979), p. 94 ss.

183 El concepto "estado prestacional" es precisado por el autor, entre otros, por analogía con las cláusulas de bien común en el derecho comunitario (VVDStRL 30 [1972], p. 43 [57]). Siguiendo esta línea, para establecer los límites del endeudamiento, G. Püttner, ebd., p. 20 ss. se remite convincentemente a las normas del derecho comunitario que excluyen la aprobación estatal "cuando las obligaciones crediticias no se hallan en consonancia con la capacidad de rendimiento permanente de la comunidad".
} 
(¡inversiones a futuro!) como también su limitación ${ }^{184}$. En esto consiste la inevitable ambivalencia del problema y las dos cabezas de Jano del tema "tiempo y cultura".

\section{Lista de abreviaturas}

BVerfG (Bundesverfassungsgericht): Tribunal Constitucional Federal

BVerfGG (Bundesverfassungsgerichtsgesetz): Ley del Tribunal Constitucional Federal

BVerfGE (Entscheidungen des Bundesverfassungsgericht): Sentencias del Tribunal Constitucional Federal

DRiG (Deutsches Richtergesetz): Ley Judicial Alemana

GG (Grundgesetz): Ley fundamental, Constitución alemana

MRK (Menschenrechtskonvention): Convención Europea para la Protección de los Derechos Humanos y Libertades Fundamentales

WRV (Weimarer Reichsverfassung): Constitución de Weimar

184 Desde la teoría constitucional es importante distinguir si el endeudamiento estatal resulta de inversiones con vistas a futuro o para sueldos de funcionarios, si se deben financiar gastos productivos o de consumo. Para un esclarecimiento legal del concepto "inversión": K. Stern, Das Staatsrecht der BR Deutschland, tomo 2, 1980, p. 1281. 